\title{
Arqueología en Cuenca: de lo medieval a lo post-medieval
}

\author{
Archaeology in Cuenca: from the medieval to the post-medieval \\ Míchel Muñoz García, Santiago David Domínguez-Solera* \\ Recibido: 11/1/2018 - Aprobado: 23/7/2018
}

\begin{abstract}
RESUMEN
Este artículo se basa en trabajos propios de Arqueología Urbana y de Arqueología de la Arquitectura en Cuenca capital realizados hasta 2015 para trazar una historia completa sobre la evolución de la ciudad desde su fundación en la Edad Media hasta el S. XX. Se integran aquí la información y las conclusiones de varios informes inéditos, entretejiéndoles en un discurso teórico sobre la evolución de este fenómeno urbano.
\end{abstract}

Palabras clave: Cuenca, Arqueología Urbana, Arqueología de la Arquitectura.

Algo que ya hemos dicho en anteriores publicaciones y que de nuevo tenemos que reiterar es que la Arqueología Urbana, que todavía hoy se entiende como sinónimo de Arqueología de Gestión o Arqueología Contractual, en realidad nació como un modelo de proyecto de investigación que tenía como objeto las ciudades que, básicamente, seguían manteniendo vida propia y no eran yacimientos abandonados (Rodríguez Temiño, 2004). El Reino Unido fue pionero en esta materia durante la II mitad del S. XX, aunque desde finales de la Edad Media tenemos constancia de excavaciones en busca del resto del pasado tanto en la propia Roma como en otros enclaves singulares. Si el concepto se ha terminado mimetizando con la intervención de urgencia, es porque estos primeros

\begin{abstract}
This paper is based on our own works of Urban Archaeology and Archaeology of Architecture in Cuenca realized until 2015 to make a complete history about the evolution of the city since Middle Age to the XX century. The information and the conclusions of several unpublished reports are integrated here.
\end{abstract}

Keywords: Cuenca, Urban Archaeology, Archaeology of Architecture.

investigadores británicos se vieron obligados a excavar no donde marcaban estrategias de investigación arqueológica, sino en aquellos lugares en los que la obra civil amenazaba la integridad física del solar y sus restos. Ello ha hecho que el concepto se exporte a otros países ya "bastardizado". Por ello, se entiende que la Arqueología Urbana no sólo está interesada en los grandes edificios monumentales, sino en todo el conjunto urbano con su planificación viaria, con sus caminos de acceso (...) y también el conjunto edificatorio urbano, donde vive la inmensa mayoría de la sociedad, sus formas constructivas, los materiales empleados, asi como todo elemento que facilite la vida urbana, como pueden ser: las canalizaciones de agua, los mercados, los hornos, las ferrerías y un largo etc... (Arizaga, 1993: 11-25).

* ARES Arqueología y Patrimonio Cultural. 
Es sugerente a título interpretativo, para hacer de la Arqueología Urbana algo verdaderamente útil para entender el concepto de ciudad como una construcción que es reflejo coherente y plasma las características culturales, sociales y económicas respectivas, en las que opera la mentalidad de una determinada comunidad, relacionarla con la Arqueología del Paisaje (CRIADO, 1993). Se trata en este caso de interpretar la ciudad intentado tener en cuenta la distinta percepción y conceptualización que de ella se tenía en sus respectivas etapas, por parte de sus constructores, habitantes y visitantes.

La ciudad es tanto un soporte de la actividad física que allí se realiza, como algo con capacidad para ser un actor social en sí mismo y en proporción a la entidad de dicha actividad. Desde la Antigüedad la ciudad, aparte de soporte de instituciones que le dan vida propia y un grado de autonomía variable, es igualmente un centro económico basado en el comercio y en la producción manufacturera, ya sea de tipo industrial o artesanal. Aunque muchos fenómenos urbanos tienen un origen prerromano, que se prolonga en la Antigüedad, la fisonomía actual de casi todas las ciudades históricas contiene más restos de la Época Medieval, Moderna y Contemporánea. Es decir, épocas históricas que han tenido una atención destacada no sólo por parte de la Arqueología, sino también preferentemente por parte de la Historia. Aunque no podemos extendernos mucho en esta cuestión, sí señalamos que el peculiar desarrollo académico de la primera disciplina, vinculada a las épocas prehistóricas, ha hecho que se la considere como una técnica o una disciplina complementaria de la segunda.

Sin embargo, aunque ambas ciencias tengan en Europa idéntico fin -la reconstrucción histórica del pasado-, ambas también tienen métodos diferentes de los que se derivan planteamientos diferentes y de los que salen dialécticas en ocasiones muy diversas. Es por ello que la Arqueología también debe de elaborar su propio discurso narrativo. Este siempre será complementario, pero sin tener que sobreponerse o someterse al producido por la Historia. Mientras la Arqueología Clásica y la Medieval hilvanan esto con mayor o menor fortuna en España, la Arqueología Post-medieval y la Industrial van un paso por detrás a la hora de generar literatura o puestos académicos específicos, pero empiezan a tener ya referentes de calidad y utilidad indiscutible (ver, por ejemplo, GUTIÉRREZ, 1997 o QUIRÓS y BENGOETXEA, 2011).

\section{Objetivos y Metodología}

Las intervenciones en Arqueología Urbana siempre tienen la limitación del propio alcance de obra, por lo que la intervención no siempre puede extenderse a todos los muros del edificio (cuerpos de fábrica) o a la extensión de todo el subsuelo del solar. En este trabajo no pretendemos explicar todos los resultados de la Arqueología Preventiva o de Gestión de Cuenca, sino únicamente construir el discurso narrativo que antes aludíamos, a la vez que aprovechamos la ocasión para dar noticia de nuestras últimas intervenciones inéditas desde 2011, ya que el resto ya ha sido objeto de varias publicaciones que se irán citando a lo largo del texto. (MILLÁN y MUÑOZ, 2007, DOMÍNGUEZ-SOLERA y MUÑOZ, 2014).

En ellas ya se manifestó que el carácter peculiar de la Ciudad Alta de Cuenca o, sencillamente, casco histórico lo define su estrecho solar entre los ríos Huécar y Júcar. Ello hace que el subsuelo se vea afectado por la búsqueda de espacio cubierto vital no solo para conformar espacios de sótano, sino incluso nuevas plantas en altura sobre los acantilados que dan a las hoces de las dos corrientes fluviales arriba mencionada. Al desaparecer los estratos de deposición terrestre en la mayor parte de su suelo urbano - las excepciones son lugares como la Plaza Mayor o la Plaza Mangana -, los depósitos que se generan a posteriori se contienen en arquitecturas que destruyeron los precedentes. Por ello, los nuevos niveles, vienen definidas por los muros que la contiene. Estos también siguen sus propios procesos de transformación que a su vez son definidos por la estratigrafía muraria. De ahí, que sea tan básico el uso de la Arqueología de la 
Arquitectura en casi todas las intervenciones, no sólo para conocer una importante parte de lo que contiene el yacimiento de la Ciudad de Cuenca, sino fundamentalmente para estructurar todo el conocimiento arqueológico que construimos científicamente.

\section{Arqueología Medieval: La Ciudad Cristiana de Cuenca}

Ya publicamos que en la ciudad de Cuenca se ha localizado cerámica de la Edad de Hierro y las excavaciones arqueológicas de la Plaza Mangana también han hallado terra sigillata, aunque desconocemos en qué tipo de contexto concreto. Sin embargo, la ciudad de Cuenca es básicamente una fundación de la Edad Media, cuyos orígenes tendríamos que poner en relación con el tránsito interno de la demarcación conocida como Cora de Santaver y el paso hacia el dominio del linaje fronterizo de los Banu Razim, cuya capital no es otra que la actual Albarracín. No nos extenderemos sobre la fisonomía de Madinat Kunka, ya que ésta ha sido expuesta en el libro "Tras las Murallas de Cuenca" (MUÑOZ y DOMÍNGUEZ-SOLERA, 2011). No obstante,

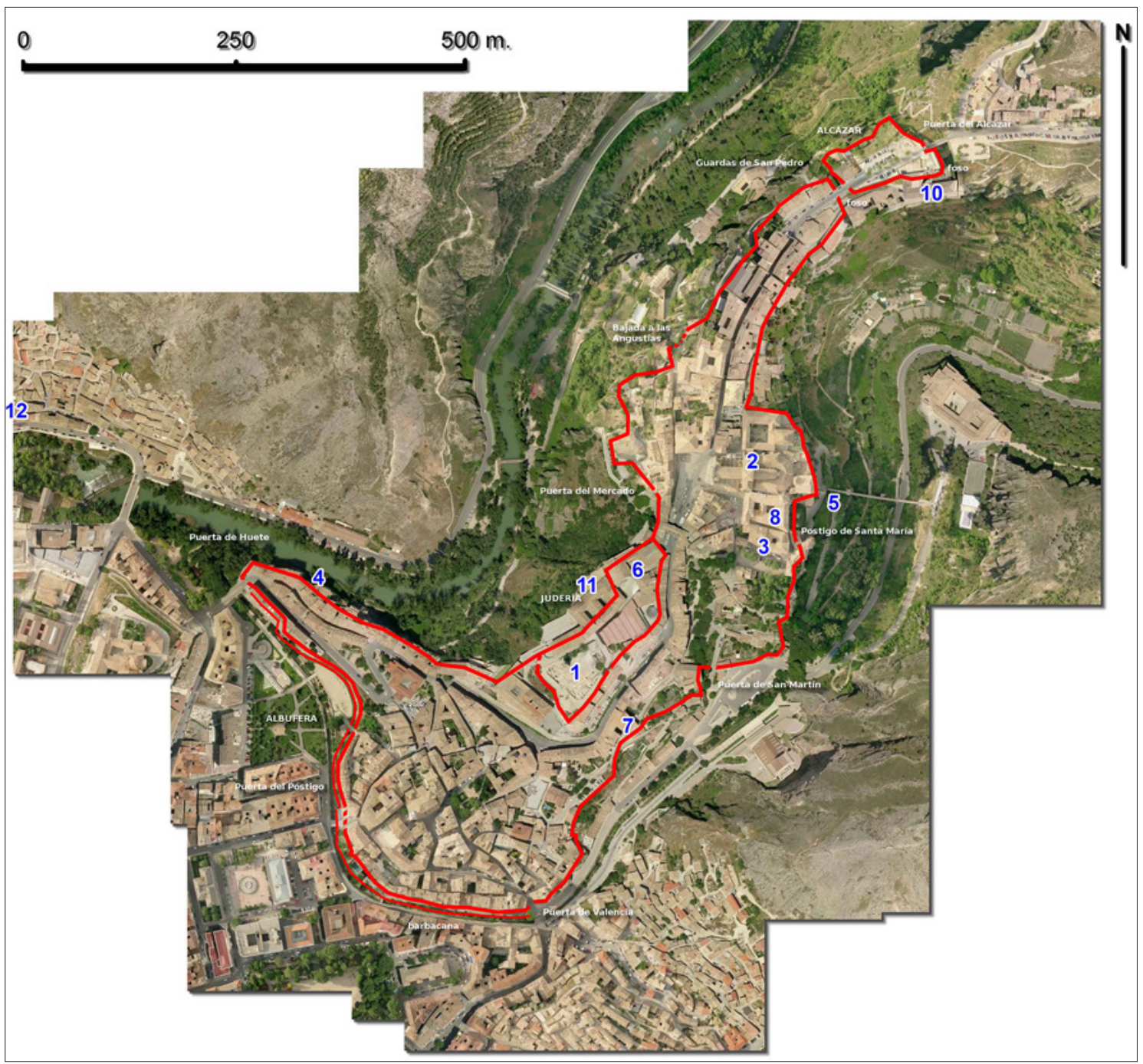

Fig. 1. Localización de los edificios y solares analizados sobre fotografía área de Google Maps, con los recintos de muralla existentes en 1300 señalados en rojo. 1: Edificio islámico de la Plaza Mangana, 2: Catedral, claustro y capilla del Espíritu Santo, 3: Inmuebles en calle Obispo Valero 8 y 10, 4: Vivienda en calle San Juan 48, 5: Puente de San Pablo, 6: Tramo del acueducto en calle del Fuero, 7: Casa del Corregidor, 8: Palacio Episcopal, 9: Vivienda en calle San Pedro 40, Casa del Arcediano, 10: Cárcel de la Inquisición, 11: Seminario de San Julián, 12: Alfar de Pedro Mercedes. 
aunque sigamos defendiendo la ubicación de la Alcazaba en el actual Castillo, sí reconocemos que la zona de Mangana -el futuro "Barrio del Alcázar" - constituyó un centro de poder importante, cuya principal manifestación es el palacio musulmán exhumado por Valero Tevar en los últimos años (VALERO TEVAR, 2010) (Fig. 2). A falta de una publicación definitiva, no nos atrevemos a especular si esta zona de poder y prestigio ya tendría que ubicarse en época taifa o no, en base a los capiteles hallados de tipo trépano, supuestamente procedente de Madina Azhara (MILLÁN y MUÑOZ, 2007), aunque también debemos valorar la posibilidad de que sea una importación toledana, ya que en esa ciudad se han vienen estudiando ejemplares similares desde hace décadas (Cressier, 1999). La monumentalidad de este palacio lo podemos ver en la sillería en tizón que se han hallado el lado Oeste del mismo.

Tras la conquista de Cuenca, por parte de Alfonso VIII, la futura ciudad no responderá al modelo de urbanismo andalusí asimilado por los reinos cristianos como Sevilla o Toledo. La razón era la poca población que había en el año 1177. Ibn Sahib ya dice que apenas había 700 almas, de la cuales muchas perecieron en el asedio y otras emigraron. La antigua Medina de Cuenca será transformada plenamente en una ciudad de urbanismo cristiano, a pesar de que parte del trazado de sus dos primeros recintos de muralla, el solar de su mezquita mayor y el solar de su alcazaba van a ser asumidos por la sociedad cristiana como sus defensas propias, su catedral y su alcázar real (MUÑOZ y DOMÍNGUEZ-SOLERA, 2011). Pero la principal manifestación castellana serán los espacios abiertos surgidos en torno a las parroquias y la organización de un parcelario con solares rectangulares, cuya fachada exterior se situará siempre en uno de sus lados menores (MUÑOZ y DOMÍNGUEZ-SOLERA, 2011: 149 y ss.).

Está constatada la presencia del rey Alfonso durante largas temporadas en su nueva ciudad y, por tanto, a él debemos que la refundase según el modelo extremeño. Es decir: a modo de un concejo de boni homini, con recursos propios para costearse una panoplia guerrera según sus posibilidades

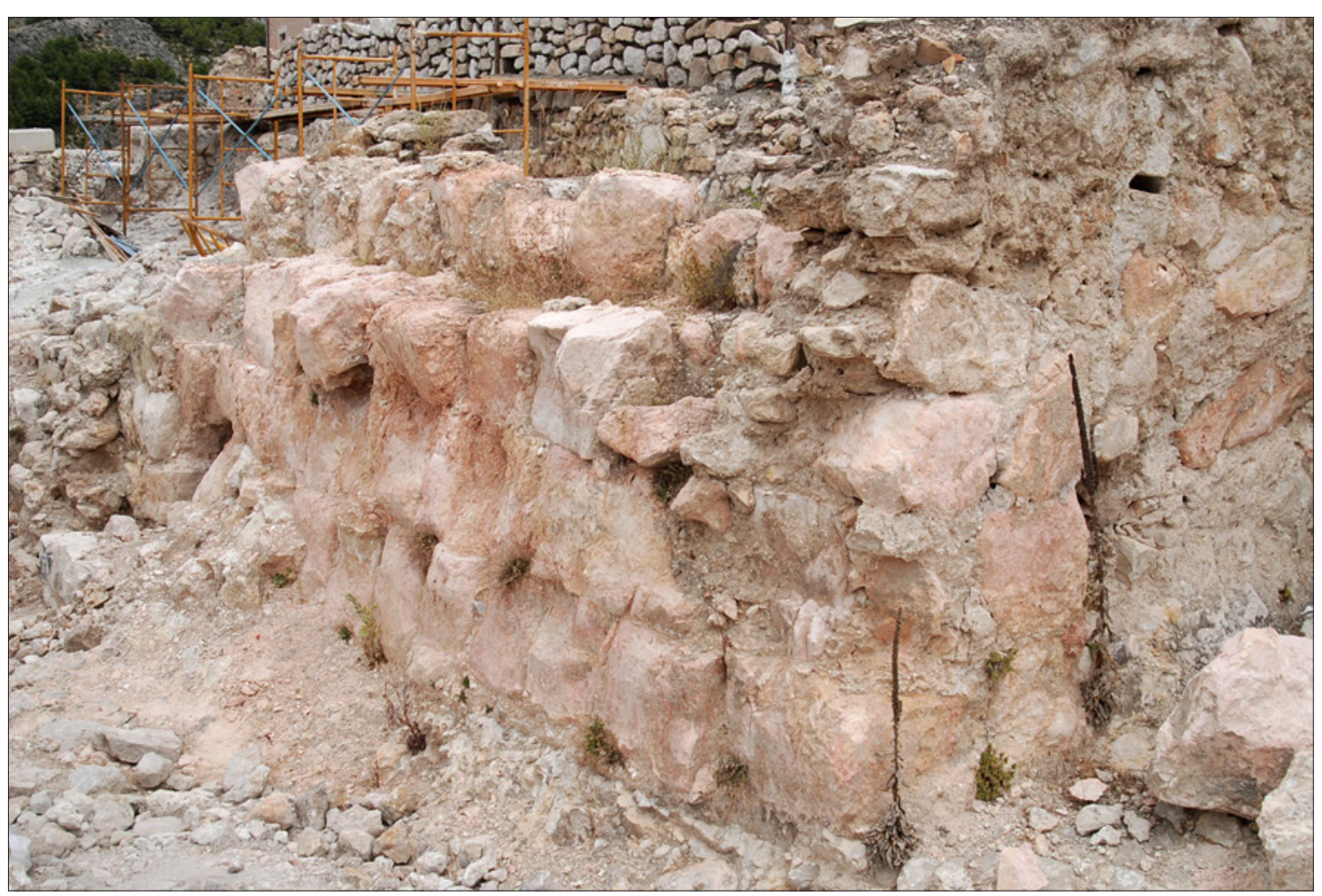

Fig. 2. Restos del palacio musulmán hallado en las excavaciones arqueológicas de la Plaza de Mangana. 
-no todos podían mantener un caballo, pero sí combatir como infantes o simplemente cuidar del ganado saqueado por la hueste concejil-, que servían como guarda de frontera e integraban el ejército real si eran convocados para ello. El modelo extremeño también tiene un urbanismo propio, que se manifiesta entre las ciudades de la Extremadura del Duero como Ávila, Zamora, Salamanca y Segovia. Su principal característica es concentrar el Alcázar Real y la Catedral en el lugar más alto y preeminente del cinturón murario (MUÑOZ, 2007). A su vez, esto genera que estas zonas cercanas a Catedral y Alcázar se localicen los barrios más pudientes y el mercado, como ocurre efectivamente en Cuenca sobre la calle de San Pedro y en el de los Canónigos de Segovia.

En realidad, Catedral, Alcázar y Parroquias no dejan de suponer la encarnación de la simbología tripartía feudal: intelecto, alma y cuerpo, que generan las virtudes de la pureza, la fortaleza y el esfuerzo, que a su vez se encarnan en los tres órdenes sociales de oratores, bellatores y laboratores (DUBY, 1980 y VALERA, 2002). Y de este modo, podríamos establecer la correlación directa de que el edificio catedralicio sería la sede de los primeros, el castillo real la sede simbólica de los segundos, mientras que la parroquia, a pesar de su carácter sacro, no deja de representar a los habitantes del concejo en su carácter más plural, pues un concejo de repoblación no deja de ser un modelo de cohesión social, en el cual, todos sus habitantes unen sus fuerzas contra el enemigo musulmán. Ello en parte se explica por la movilidad social que suponía la práctica de la guerra durante el proceso de la llamada "Reconquista", ya que el botín derivado de ella ofrecía muchas posibilidades de enriquecerse. Y como manifestación también simbólica de esa cohesión estaría la propia muralla, independientemente de cumplir con otras funcionalidades y necesidades. Esta es un auténtico cinturón construido que aglutina a todos sus habitantes, independientemente de su posición social. Además, distingue el espacio de la ciudad del que no lo es, con la salvedad del fenómeno de los arrabales extramuros. Y de su papel en la mentalidad cristiana medieval dan fe las múltiples representaciones visuales de la época, en que la ciudad parece identificada en primer lugar por sus cinturones murarios.

La "fuerza" del concejo trató de ser controlada tanto por el Rey como por el Obispo. A veces, sus motivos divergían mientras otras convergían en la más pura expedición de conquista. Sólo tenemos que pensar en el Obispo de Ávila, que estuvo presente en el sitio de Cuenca con las milicias de esa ciudad, y una dignidad conocida como Pedro que presumiblemente comandaría la hueste de Toledo... Todo ello según el testimonio de Giraldo (MUÑOZ y DOMÍNGUEZ-SOLERA, 2011). En parte por esto, ambos poderes también proyectaron su dominio mediante formas arquitectónicas que no son otras que el propio alcázar y la propia iglesia mayor. Los grandes magnates, la más genuina aristocracia que se identifica con el grupo de los bellatores, en los reinos de León y Castilla, durante la Plena y Alta Edad Media, nunca tuvieron el mismo poder y grado riquezas que la nobleza francesa o alemana (GERBET, 1997: 39-49). En la ciudad sólo actuaban como representantes del monarca, de ahí que no dejen huellas monumentales en las ciudades de realengo de los S. XII y XIII.

En el caso de Cuenca, tanto rey como obispos no buscaron el punto más monumental para la nueva catedral, sino que se impusieron elocuentemente sobre la antigua mezquita musulmana construyendo el templo principal cristiano. Desde los tiempos de la conquista de Toledo, esto constituía un ejercicio simbólico de conquista cultural y era algo práctico a la vez, ya que proporcionaba un solar con ciertas condiciones con poco esfuerzo constructivo. Respecto a la sede real, la cosa no parece tan automática, pues el "Fuero de Cuenca" lo que menciona es el palatium como morada. Tenemos nuestras dudas a la hora de identificarlo ya con el Alcázar posterior. Es cierto que el urbanismo extremeño es de constitución muy lenta: por ejemplo, el castillo de Zamora no se levanta hasta los tiempos de Fernando III (DE CASTRO y CUADRADO, 2012), sin que sepamos de alguna otra fortificación anterior 
que cumpla con tal cometido. En el caso de Cuenca, no tenemos certeza de la conversión de la Alcazaba en Alcázar hasta un año después de la muerte del rey Alfonso VIII, cuando su hijo manda levantar una capilla en la que es ya su residencia fortificada. Tal capilla, a nuestro entender, corresponde con los restos excavados en los años 80 y 90 del S. XX, aunque fueron interpretados entonces como estancias indeterminadas (SOLÍAS, HUÉLAMO, y COLL, 1990: 25-30).

De lo que sí es testigo la Crónica del Arzobispo Rodrigo Jiménez de Rada, es de la construcción de la muralla de la que denominamos Fase III de Cuenca -centrada entre 1177 y 1236 (MUÑOZ y DOMÍNGUEZ-SOLERA, 2011: 154)-, cuando habla de que Alfonso VIII aumentó la altura de las murallas y las envolvió con segura protección. Sin embargo, la obra no va ser célere, pues en el mismo "Fuero de Cuenca" se cita el muro que se estaba construyendo en el arrabal. Tengamos presente que se anota en la versión sistemática de la carta foral, la conservada en la biblioteca del Monasterio del Escorial. Según Rafael Ureña y Smenjaud (1917) se fecharía el "Fuero" entre 1249 y 1250 , por referirse en el listado final de jueces que fue redactado en tiempos del Juez Alvar Pérez, que ejerció su mandato en esos años. Esto también nos lleva a plantearnos si la construcción de la Judería en Mangana con su muralla es producto del reinado de Alfonso VIII o tendríamos que llevarla a los de Fernando III, cuando se construyen estructuras similares en algunas ciudades andalusíes recién conquistadas, como es el mismo Castillo de los Judíos en Córdoba (MUÑOZ y DOMÍNGUEZSOLERA, 2011).

Hay que apuntar que tanto murallas como catedral se gestan en un proceso similar de ejecución. Esta última se comenzó entre 1194 y 1204 y ya ha sido objeto de varias publicaciones por nuestra parte, en las cuales damos una secuencia completa desde su fundación a las restauraciones más recientes (MUÑOZ, 2009 y MUÑOZ y DOMÍNGUEZ-SOLERA, 2010). En las mismas hemos puesto de manifiesto tres proyectos diferentes para la Edad Media, aunque existen más fases constructivas. Dejando a un lado la Fase I, que es la de Mezquita de Cuenca, nos referimos primero al que va desde la fundación cristiana al crucero, y que estimamos que estaría en pleno rendimiento hasta 1236. Después se realizaría un parón que duraría hasta que toma posesión el nuevo Obispo Mateo Reynal en 1247, siendo éste el impulsor de los trabajos de las II mitad del S. XIII -fases IIIa y IIIb-, a cargo de los maestros Enriquey Juan Pérez. Se terminaría el Claustro y el brazo mayor y habría que esperar para una nueva fase a 1480, cuando el maestro Cristóbal comienza la realización de la girola -Fase VI-.

\section{Sobre el Claustro Catedralicio}

Este claustro gótico desaparecido correspondería a la fase III catedralicia y para estudiarlo no tenemos que acudir al análisis constructivo del patio porticado de la época moderna que sí se conserva, sino a otra construcción adyacente al mismo. Nos referimos a la Capilla del Espíritu Santo, mandada construir hacia 1572 y terminada en 1576 (ROKISKI, 1985). Durante nuestros trabajos de obra en la cubierta de 2012, comprobamos que las unidades estratigráficas murarias (UEM) de los cuerpos de fábrica 128, 129, 130 y 131 -los que constituyen la caja del cimborrio que acoge la media naranja interior- presentaban tal cantidad de elementos reaprovechados, que dejan pocas dudas al respecto: sus muros se levantaron en su mayor parte con elementos reaprovechados procedentes del derribo del claustro gótico preexistente, que se había comenzado a desmontar en 1548 (ROKISKI, 1985). Se hallaron además una ménsula y una peana, ambas piezas de estilo gótico, pero son las marcas de cantero y las huellas de las herramientas medievales las que certifican todo esto. En la Catedral de Cuenca la gradina se aplicaba sobre todas las piezas arquitectónicas finamente labradas, tuvieran decoración o no (Fig. 3).

Las huellas de este instrumento presentan un grosor variable. Y aquí sí podemos distinguir entre las que estaban a la vista y las que no. Durante los controles arqueológicos realizados sobre las bóvedas de la nave central 

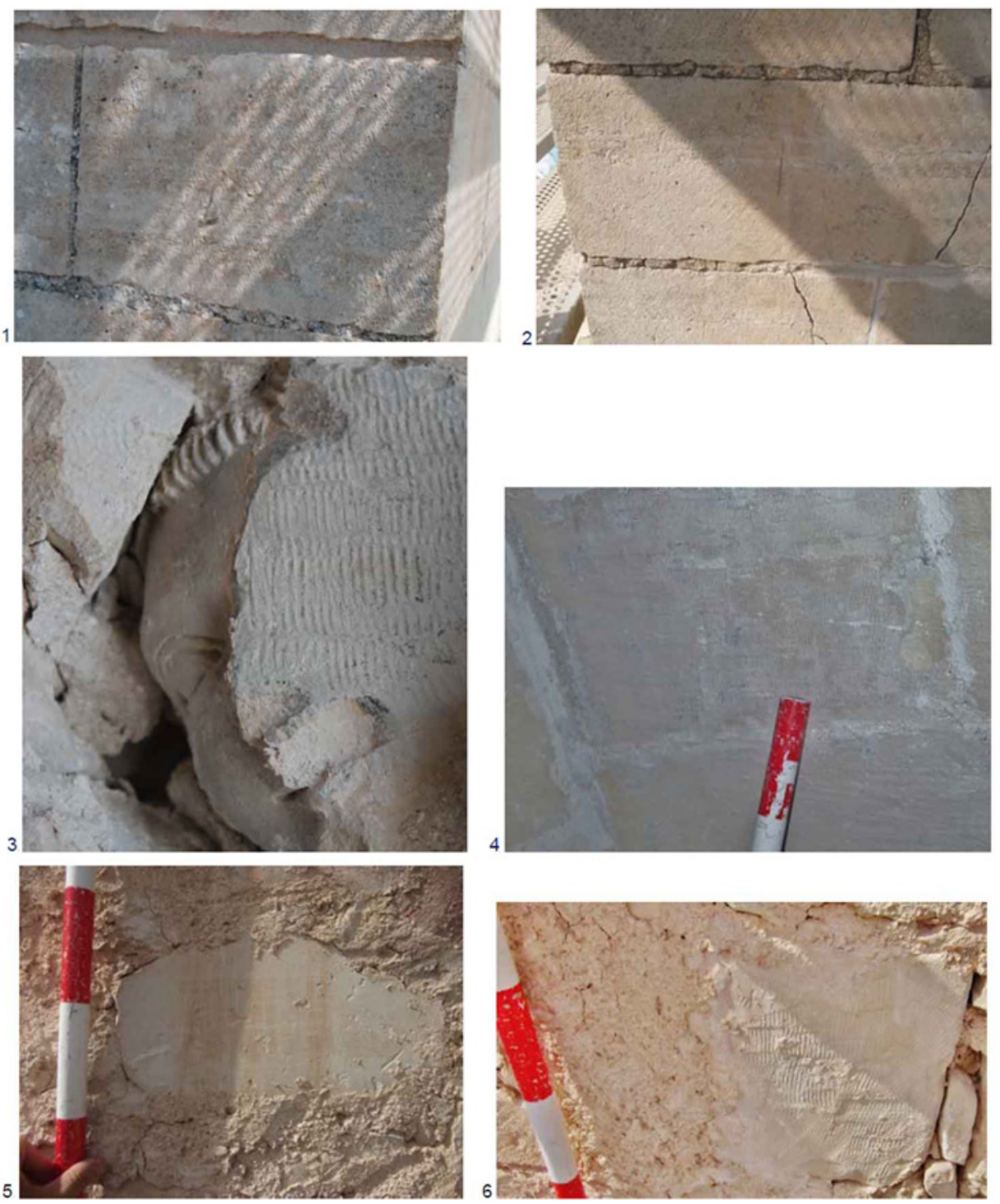

Fig. 3. Sillares del Cimborrio de la Catedral de Cuenca con huellas de gradina (fotografías 1 y 2, fases II y III de la secuencia catedralicia, UEM 1760 y 1761). Adviértase en la fotografía 2 el desgaste de las marcas de herramientas. Contrasta con la fotografía 3, que no ha sido sometida a las inclemencias exteriores, ya que la escultura del capitel cortada, alisada con gradina y con huellas de unos $5 \mathrm{~mm}$ fue posteriormente tapada por una capa de cal. La fotografía 4 pertenece a uno de los arcos de la nave central que se abren a los rosetones. Se ha preservado una huella similar. Ya las fotografias 5 y 6 pertenecen a la UEM 744 del cuerpo de fábrica 128 de la Capilla del Espíritu Santo. La 5 parece un antiguo sillar fragmentado con huellas de entre 3 y $4 \mathrm{~mm}$, mientras que la pieza de la foto 6 ya parece producto de una gradina más basta.

de la Catedral -en el año 2006-, advertimos que los grosores de las huellas llegaban a los 5 y $6 \mathrm{~mm}$, en contraste con las huellas en piezas de partes más bajas, que están entre los 3 y $4 \mathrm{~mm}$. Es siempre una toma de datos que se debe interpretar con mucho cuidado, pues en realidad sólo si encontrásemos un juego de herramientas canteriles completo del S. XIII, podríamos contrastarlo con cierta seguridad. Por ello, también tenemos que tomar en cuenta la mayor o menor fuerza del cantero o el grado de erosión al que ha sido sometida la pieza. No obstante, la existencia de estos dos tipos de huella nos hace pensar 
en dos tipos de gradinas, cuyos dientes son aplicados según el destino final que vaya a tener el bloque de labrar. Es evidente que una herramienta más liviana implica un mayor tiempo de ejecución respecto a otra más basta. En las fábricas de la Capilla del Espíritu Santo, estas huellas están tanto sobre piezas labradas completas, como sobre mampuestos. Es fácil deducir que su forma es resultado de la fragmentación de sillares y otras formas canteriles, que se produce con el desmonte del claustro medieval.

No es hasta 1276 cuando se hace referencia al antiguo claustro gótico, año en el que se dice que el obispo Diego Martínez había establecido allí la misa de Nuestra Señora, la de los sábados y la de Difuntos, para la que se reservaban los lunes; el cabildo celebraría, a su vez, una procesión por el Claustro, el domingo, portando cruz de plata. Palomo Fernández también señala que en 1279 estaba en plena ejecución la Sala Capitular destinada a la claustra (PALOMO, 2002: 30).

En base a estas referencias documentales, tendríamos que situar la construcción del claustro gótico entre las fases III A y III B, atribuidas respectivamente a los mencionados maestros Enrique y Juan Pérez. Una manera de comprobarlo materialmente es contrastar la colección de marcas de cantero estudiadas en las cubiertas de la Capilla del Espíritu Santo con las identificadas en el cimborrio catedralicio, por nosotros mismos en los trabajos del año 2008-2009. También han de compararse a las marcas documentadas por Noguera Campillo (NOGUERA, 2012).

Este último autor presenta una secuencia temporal de la construcción del edificio medieval, que difiere totalmente con nuestros postulados. Su interpretación se construye en torno a una fuente desaparecida, el Catálogo de Epígrafes que Trifón Muñoz Soliva examinó en su tiempo. Uno de ellos hacía mención a que el Obispo Mateo Reynal terminó la Catedral en 1256, algo que entra en contradicción con la exención de pechos de 1270 para los bueyes que pastan en los prados del Concejo conquense y se empleaban en las obras de la
Catedral y del Alcázar de Alfonso X. Por ello, esta noticia tan tardía y no comprobable fue valorada como dudosa por Palomo Fernández y por León Meler (LEÓN, 2006). Además, nuestros propios estudios revelan suturas, cortes y lo que hoy entenderíamos como cambios de proyecto, indicios que sólo pueden ser comprendidos en un amplio margen temporal que implicase casi toda la centuria de 1200. Y dentro de este cambio también habría el parón de obras que certifica la sutura UEM 1751, cuya separación y dilatación respecto al plomo del muro del mismo cimborrio catedralicio sólo proviene de una interrupción prolongada que marca el paso de la fase IIb a la Illa en el cimborrio de Cuenca (MUÑOZ y DOMÍNGUEZ-SOLERA, 2010).

Tal interrupción de obra tiene un contexto: en 1236, unos fronteros aprovechan la sorpresa para hacerse con la Axarquía de la ciudad de Córdoba. La noticia llegó a todos los confines del reino muy rápidamente y el rey Fernando III el Santo junto a magnates y otros personajes envían refuerzos. Entre ellos acude el obispo de Cuenca Gonzalo Ibáñez, martillo de sarracenos, que parece más líder militar que prelado. En el asedio de la antigua capital del Califato comandará la hueste conquense y, durante diez años, estarán presentes en la conquista de Requena, Andalucía y el Reino de Murcia junto al infante Alfonso (BALLESTEROS, 1949). Serían diez años -que coinciden con su obispado- en que todos los esfuerzos financieros se destinaron a los propósitos guerreros. Por ello, también hemos señalado esta fecha para el final de la fase III de la construcción de la muralla. Y por tanto, la referencia a las obras defensivas de la cerca que se cita en el Fuero de Cuenca, habría que enmarcarse ya en la Fase IV de mediados del S. XIII.

Pero volviendo al edificio de la iglesia mayor, de haber continuado las obras sin esta interrupción hubiera sido imposible un cambio tan brusco entre un gótico inspirado en el Císter para cabecera y crucero y otro inspirado en los preceptos y formas que se hacían por entonces en París. Éste sería el que promovería el siguiente obispo Mateo Reynal a partir de 1247, cuando trae de la 


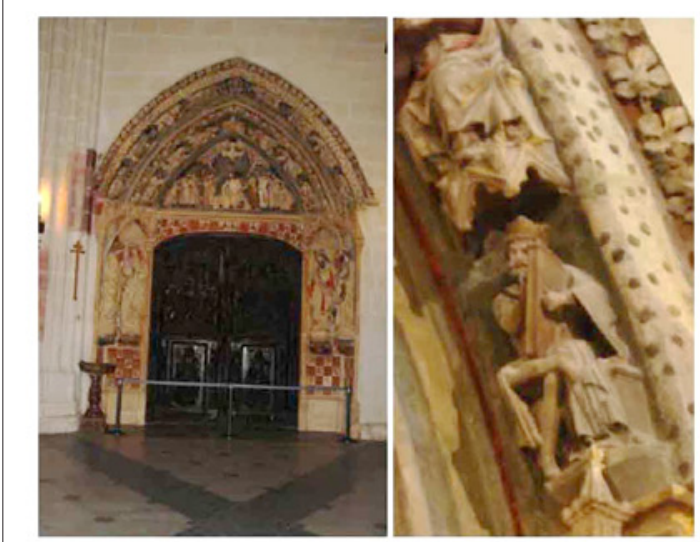

A

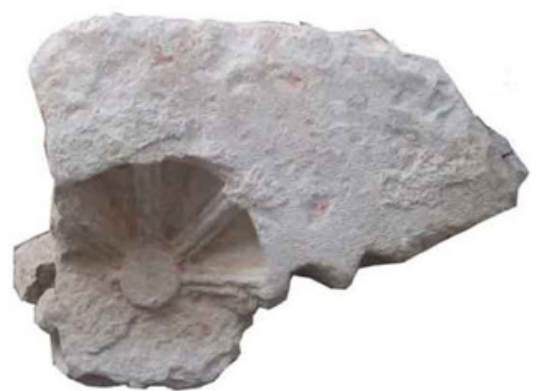

B
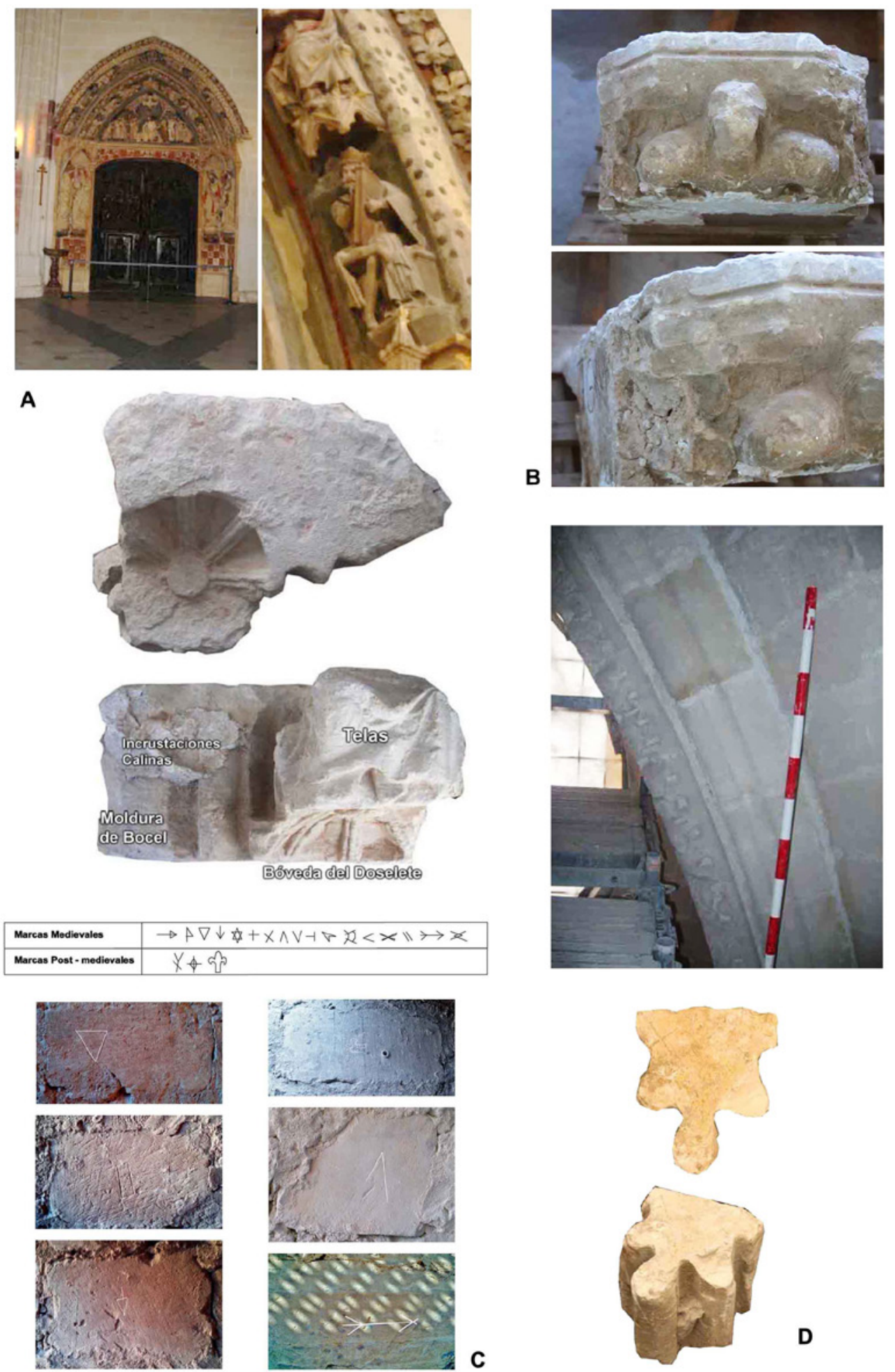

D

Fig. 4. A. Portal del Claustro Alto de Burgos con un detalle de la arquivolta con doselete y bocel. Nótese que el "patrón" entre bovedilla y telas también se repite en la pieza extraída de la cornisa de la Capilla del Espíritu Santo en la parte de abajo. B. Ménsula del personaje antropomorfo con atributos a los laterales de los hombros que representan las plumas de alas propias de los ángeles,

los arcángeles, los serafines o los querubines. C. Colección de marcas de cantero hallada en los muros de la Capilla del Espíritu Santo. D. Arquivolta de uno de los arcos de la nave central decorada con bocel y pieza de nervio hallada durante la intervención de la Capilla del Espíritu Santo, tanto en planta como en perspectiva. Nótese como la marca de cantero está en una cara no vista. 
Ille de France al Maestro Enrique (MUÑOZ y DOMÍNGUEZ-SOLERA, 2010 y 2011). Noguera no contempla los contextos históricos para su modelo de interpretación que, aparte de la fuente tardía, construye a través de aspectos técnicos y estilísticos no determinantes. Por otro lado, es de justicia reconocer el mérito de Noguera por haber descubierto la vinculación entre la catedral de Sigüenza y la de Cuenca en sus primeras fases, además de haber definido con precisión el sistema de evacuación de aguas original de las cubiertas del edificio (NOGUERA, 2012).

Además de su uso litúrgico y de representación, sabemos que también el claustro gótico de la Catedral de Cuenca tuvo un uso funerario, pues en los últimos años del S. XIII - S. XIV, el chantre Juan Peláez disponía su enterramiento en la Claustra de Sancta Maria, alli do yaze mio ayo de capilla, don Johan..., lo cual hace que Palomo acierte al decir que es la prueba de que previamente existía un espacio definido y habilitado para ello (PALOMO, 2002: 43 y 30).

En los claustros funerarios de las catedrales de Burgos y León existen ángeles en las ménsulas donde se apoyan los nervios de las bóvedas, que simbolizan el tránsito desde el sepulcro al Más Allá. La cuestión de los ángeles es interesante, puesto que la ménsula recuperada y que estaba reaprovechada en la cornisa de la Capilla del Espíritu Santo, la interpretamos como tal. Correspondería a un busto con cabeza y los brazos insinuados, estando las alas de plumas en los laterales. Sin embargo, esto no demuestra que la estructura del claustro funerario de Cuenca pudiera haber integrado nichos retranqueados en el muro interior, pues si nos fijamos, la ménsula en la que se inserta dicho ángel tiene un equino y un ábaco con forma semi-octogonal, forma completamente diferente a la pieza rectangular con saliente que presentan los soportes de los nervios góticos en León y Burgos.

Más bien, este ángel no parece estar cumpliendo funciones simbólicas de tránsito hacia el cielo -recordemos que en las representaciones de los juicios finales son estos seres alados los que hacen sonar las trompetas que despiertan a los difuntos-, sino más bien desempeñaría un papel de escolta o soporte de un personaje sacro o profano. Existen paralelos de ello: son la representación de la Sinagoga y la Ecclesia en el pórtico del Juicio Final de la Catedral de Lincoln en Inglaterra (WILLIAMSON, 1997). Ambas figuras están sostenidas con ménsulas similares. Así pues, estaríamos ante el sostén de una estatua que quizá se ubicaría en los muros interiores del claustro -recordemos las estatuas de reyes e infantes en el claustro de la Catedral de Burgos- o en el portal mariano que refiere la documentación y del que Palomo (2002) no puede precisar la cronología, puesto que no se da ninguna fecha en las alusiones escritas y cotejadas por esta historiadora. Esta portada, presumiblemente, abriría los espacios de la basílica catedralicia al claustro.

No deja de ser mera conjetura que la ménsula del ángel pueda pertenecer a esta portada "claustral". Sin embargo, la cuestión se sustenta en argumentos más sólidos en el caso del doselete hallado durante la obra. Fijémonos en su parte superior exterior, la que acoge a la bovedita de crucería interior. Se trata en realidad de telas, con las que podemos establecer otro símil en la Portada del Claustro de la Catedral de Burgos. Es la entrada por la que se accede a la galería superior desde el brazo Sur del crucero. En ésta se aprecia cómo sus arquivoltas unen en una sola pieza los doseletes junto al ropaje y cuerpo de la figura superior.

Si además en la pieza recuperada de la Capilla del Espíritu Santo observamos la moldura lateral en bocel, existen pocas dudas para suponer que pertenecería a una arquivolta de una portada monumental, articulada con personajes menores en sus propios arcos quizá un coro o cielo musical-. Lógicamente se hace razonable pensar que dicho doselete podría estar integrado en la desaparecida portada consagrada a Santa María, que vestía el Claustro Gótico Conquense. No obstante, nunca debemos abandonar la prudencia y admitir las debidas reservas de que las piezas descritas pudieran haber pertenecido a otro 
programa arquitectónico como la capilla del Corpus Christi, que se levanta en la centuria de 1300. Ésta no es otra que la que Juan Hurtado de Mendoza refundará como Capilla del Espíritu Santo en 1440 (IBÁÑEZ, 2006). Palomo (2002) señala que ésta fue convertida en sala capitular en 1399 y así seguiría hasta la dicha entrada en escena de la familia Hurtado de Mendoza y la erección esencial de la Capilla del Espíritu Santo de finales del Renacimiento.

En cuanto a la cubrición del claustro gótico conquense mediante bóvedas de crucería, podemos aludir a la pieza de nervio recuperada en la cornisa de la Capilla del Espíritu Santo, con una sección de bocel completo o baquetón, medios boceles a los lados y talón. La preferencia por dichos boceles es también una constante en los tramos de bóveda de la nave central de la II mitad del S. XIII, lo cual, por contemporaneidad, abre la posibilidad de que ésta sea uno de los fragmentos del claustro primigenio. Pero de nuevo nuestras reservas de prudencia hacen que recordemos que en el S. XIV se siguen utilizando tales diseños y, por tanto, también podría haber pertenecido al espacio reservado al Corpus Christi y del cual nada sabemos de su morfología. Por último, tenemos noticia de obras en los pilares del Claustro en 1406, llevados a cabo por el maestro Juan Alfonso, sin que podamos precisar más (PALOMO, 2002: 30 y 31).

\section{La Vivienda Medieval a través de los Inmuebles de Obispo Valero}

Respecto a la vivienda medieval de Cuenca, la calle Obispo Valero ha dado dos hallazgos afortunados en los últimos años. En el informe arqueológico de estudios previos del inmueble no 10, adscrito al Museo Arqueológico, desarrollamos una completa lectura de paramentos. Los restos medievales se localizan lógicamente en el piso bajo, en una serie de unidades funcionales con bóveda de medio cañón y estructuras de madera, yeso y mampostería. Corresponde a finales del S. XIII o ya al S. XIV, puesto que todo el edificio se está apoyando en la antigua Casa del Curato, donde en uno de sus muros hemos localizado una antigua puerta cegada (Cuerpo de Fábrica CF 15, UEM 19 I). La puerta sería parte de la fase I, la más antigua. Las fases II y III se situarían en otro momento posterior de la centuria de 1300 y destaca sobre todo la bóveda en piedra mentada UEM 231 en la Unidad Funcional 7. Con esta habitación se conformaría una nueva lógica espacial, pues se abre una nueva entrada (Elemento Arquitectónico EA 239), que se soluciona en dintel leñoso. A nuestro juicio, no se descarta que ésta sea una solución posterior y que la entrada al edificio se resolviera en un dispositivo de acceso más aparente. No obstante, en la estancia no hay nada que indique que el edificio desarrollase tramas más allá de lo que hoy entendemos por arquitectura tradicional. Las fábricas no pasan de una mampostería con piezas cuyo manejo no implica grandes dispositivos de elevación y pueden ser manipuladas con soltura por las simples manos de un albañil. Respecto a la sillería de UEM 184, que se ha estudiado en la Unidad Funcional 8 (CF 17), son piezas que, si no son reaprovechadas, tampoco se salen de los patrones corrientes de la Edad Media. Su funcionalidad resuelve básicamente un problema de cimentación.

Por ello, interpretamos que esta potente cubrición en bóveda se dispuso con un fin estructural, que no es otro que soportar las alturas que habría encima, es posible que similares a las actuales. Es también plausible que fuera empleada en origen como cuadra o que también albergara un taller artesano (Fig. 5). En cualquier caso, es algo que sólo excavaciones arqueológicas podrían aclarar. Aparte de esto, lo destacado es que la lectura estratigráfica ha detectado una considerable actividad constructiva en el espacio de 100 años, si atendemos tantos a las reformas de la entrada EA 177, que comunica las unidades funcionales 8 y 9 , así como las distintas escaleras que suceden en la primera de las células espaciales -recordemos como ejemplo la que acogía el arco irregular UEM 177, posteriormente modificada-. Es posible que al estar situado en un espacio preminente de la ciudad - se adosa al Palacio Casa del Curato, al otro lado de la calle tendría el Palacio Episcopal y la Catedral-fuera un solar muy demandado y 


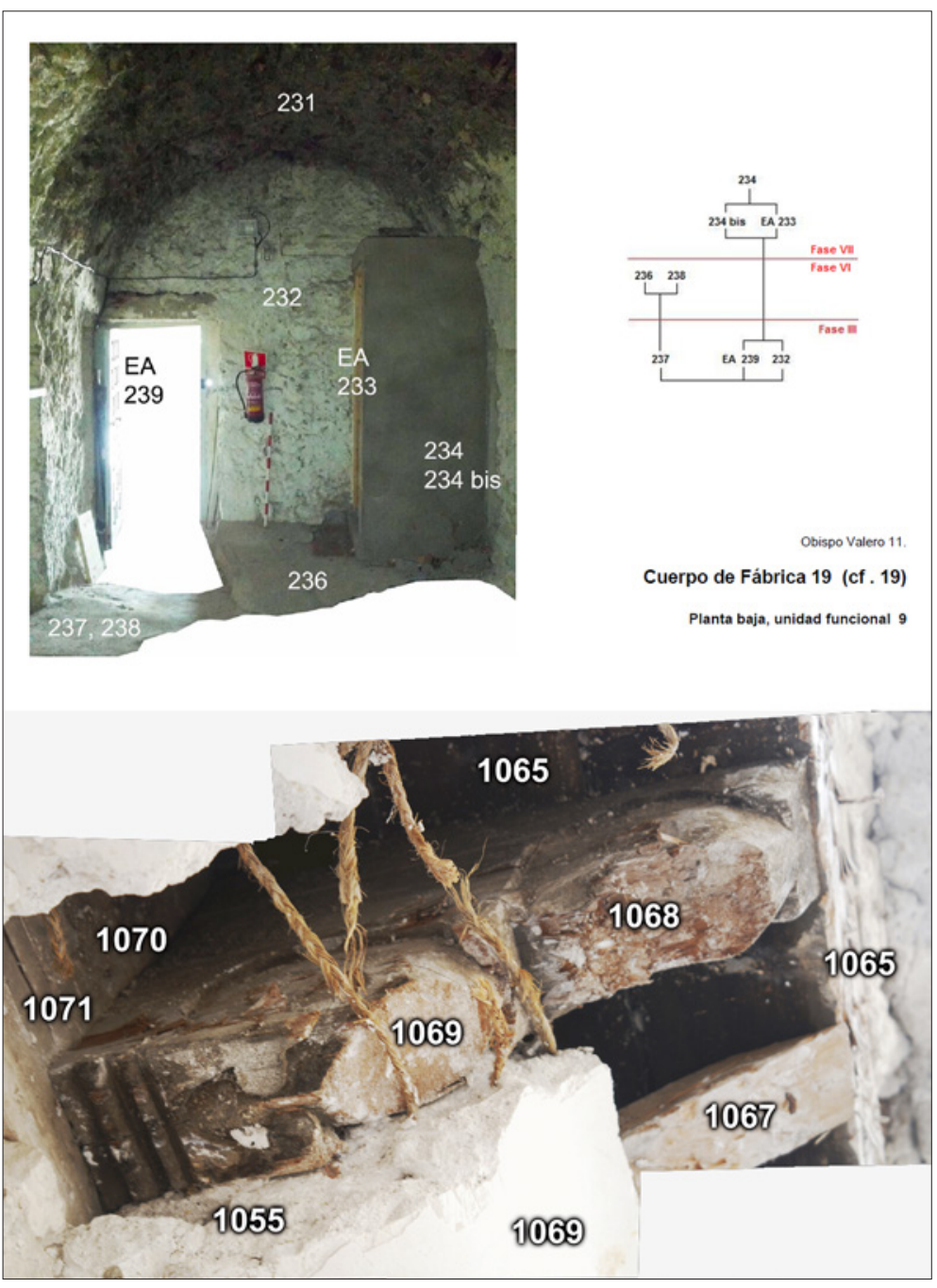

Fig.5. Bóveda UEM 231 que podría corresponder a un antiguo taller artesanal o una cuadra en Obispo Valero 10 (arriba) e individualización estratigráfica de uno de los canes localizado en la fachada del inmueble contiguo Obispo Valero 8.

susceptible de cambiar en repetidas ocasiones de propietario y, por supuesto, de uso.

Por último, nos gustaría comentar que la utilización de aparejos en piedra y los ladrillos recuerdan a soluciones que vimos en uno de los muros de cierre de la Sala Capitular de Invierno de la Catedral y en la fachada de la misma Casa del Curato. ¿Tenemos que empezar a plantearnos que la construcción de vivienda doméstica del S. XIV en la ciudad de Cuenca hizo más uso de materiales sólidos que de los entramados y estructuras enjauladas de madera en boga durante la centuria siguiente? Queda mucho por investigar a este respecto.
Si estos materiales de yeso, piedra y ladrillo están en Obispo Valero 10, la sorpresa es que en el inmueble contiguo, Obispo Valero 8, hicieron acto de presencia los materiales asociados a los tradicionales enjaulados de madera. A priori, nos parecía más bien una construcción propia de finales del S. XIX y principios del S. $X X$, por su enlucido amarillo y sus cercados blancos en lienzos y cornisas simuladas. Sólo el potente voladizo que cubre parte de la calle podría habernos advertido de que, en realidad, sus revestimientos eran una capa superficial que escondía una estructura de vivienda bajo-medieval.

Durante los controles arqueológicos de 2011 para la ocultación del cableado en las fachadas de la Plaza Mayor y las calles adyacentes, se procedió a abrir la potente moldura de yeso de este edificio a la altura de la primera planta. Y lo que se descubrió fue una estructura de dobles canes de madera con cronología medieval que podríamos situar en un contexto del S. XV. En esta centuria se escribió que la "bivienda desta cibdad es cara e costosa", lo cual propició que algunos maestros fueron muy reconocidos y obtuvieron el aprecio del Concejo. Concretamente, en relación a la importancia a los entramados y enjaulados de madera mentados, Juan de Córdoba, a parte de su maestría, fue valorado por su capacidad para atajar incendios. Nótese que era carpintero y entendía de todos los males que podían afectar a las estructuras de madera (ver para todo esto último SÁNCHEZ BENITO, 1997). 
Los canes inferiores sobresalen $30 \mathrm{~cm}$. de la fachada de la planta baja y tiene una sección de $12 \times 18 \mathrm{~cm}$. Tiene la típica forma estilizada del perro con las garras terminadas en punta. Estos mismos tipos de canes los podemos apreciar en el Palacio Episcopal de Cuenca, pues pertenecían a edificios adosados a la catedral que ya existían mucho antes de la construcción del claustro de este edificio. El can superior tiene una sección de 18,5 x $19 \mathrm{~cm}$. $\mathrm{y}$, sobresaliendo hacia fuera, $50 \mathrm{~cm}$. Tiene los mismos rasgos estilizados, sólo que representa un toro con los cuernos achatados al frente. Aunque no idénticos, existen otros similares en la Plaza Mayor en un edificio que hace esquina con la calle de San Pedro. Los dobles canes se intercalan a intervalos de $37 \mathrm{~cm}$ y se apoyan sobre una viga carrera de $7 \mathrm{~cm}$ de ancho. A su vez los canes son fijados entre carrera y carrera mediante otras piezas de madera que tiene un ancho de $28 \mathrm{~cm}$. Sobre esta estructura se aparejaba un enjaulado o entramado de pies derechos y jabalcones. El relleno entre piezas leñosas se efectuaría mediante encofrados de yeso. Todo esto apoyaría sobre los muros de la planta baja que se resuelven en mampostería concertada. Este esquema de enjaulado sobre muro de albañilería cubría el mayor porcentaje de vivienda construida en la Cuenca de la Edad Media. Es hora de adelantar cronologías; pero antes, de hablar sobre los yacimientos y edificios que parten del S. XV, es menester que adelantemos unas líneas sobre la desconocida e ignorada Arqueología Post-medieval, si es que queremos seguir embarcados en la tarea de construir una línea narrativa y teórica sobre la cultura material de la ciudad de Cuenca.

\section{Arqueología Post-Medieval}

La Arqueología Post-medieval o de las Sociedades Modernas engloba el estudio de la cultura material entre las centurias de 1500 a la de 1800 (CROSSLEY, 1990). Sin embargo, para The Society for Post-Medieval Archaelogy no se trataría tanto de dos estancos sino de uno mayor que engloba el amplio margen cronológico que iría desde los tiempos tardomedievales hasta los actuales. Es decir, se pretende considerar y sistematizar toda la cultura material de las dos divisiones históricas - edad moderna y contemporánea - que más conocimiento histórico se tiene. Ello en realidad nace del encuentro de la PostMedieval Archeology británica y la Arqueología Histórica desarrollada fundamentalmente en USA. Esta última parte de la irrupción colonial europea sobre sociedades aborígenes en el Nuevo Mundo. En nuestro país hay incluso autores que se adscriben a esta tendencia (AZKÁRATE y ESCRIBANO RUIZ, 2010). Sin embargo, desde nuestro punto de vista, esta unión plantea más problemas que resuelve. Pensemos que las amplias repercusiones que tuvieron las desamortizaciones y las reformas liberarles del S. XIX, supusieron tantos cambios sociales, que motivan nuevos contextos en los que enmarcar y explicar la cultura material de entonces. No importa que la técnica de cerámica esmaltada con decoración azul de la centuria de 1800 sea prácticamente la misma que la producción del S. XVI en Talavera de la Reina. Lo importante es que la incipiente y lenta industrialización supondrán nuevas formas de distribución, que se desarrolla desde la base de núcleos de población más nutridos y nuevas infraestructuras impulsadas por estructuras políticas, sociales y mentales diferentes a las del Antiguo Régimen. Por ello y por otras muchas razones, aquí vamos a mantener la división entre Arqueología PostMedieval e Industrial.

La Arqueología del periodo moderno existe en España: el ingente patrimonio cultural conservado de los tiempos modernos y la aplicación al mismo de la metodología arqueológica dan fe de ello. Pero la Arqueología Post-medieval española camina sin rumbo y carece de sistemática. Esta ausencia de conocimientos ordenados y articulados posterior a la Arqueología Medieval se explica, en parte, por el desinterés de la historiografía moderna de nuestro país, así como por el efecto pantalla de la Historia del Arte, que no deja vislumbrar la necesidad de este estanco arqueológico, ya que normalmente la arquitectura es parcela tradicional de los estudios artísticos, del mismo modo que a la cerámica y al mobiliario se los engloba dentro de las llamadas "artes menores". 
Para construir una Arqueología Postmedieval ordenada y sistemática no faltan ni fuentes, ni material elaborado: hay muchas memorias de intervención arqueológica en todas las provincias de España que contienen materia prima para tal efecto. Pero también necesitamos de un marco teórico y también de un punto cronológico en el que comenzar el discurso, pues no podemos olvidar que este estanco del saber o disciplina es una arqueología de periodo.

Un aspecto que hace diferente a la Edad Media y la Edad Moderna es el alto grado de poder que llegan acumular los estados, solo comparable hasta la fecha a los imperios de la antigüedad (MUÑOZ, 2009). El desarrollo económico y financiero de los capitales bancarios vino acompañado de los inicios de la expansión europea, que en el S. XVI se centraron en la creación de los imperios español y portugués, llegando a estar en manos de un solo monarca en tiempos de Felipe II, Felipe III y Felipe IV. Ello estimuló la demografía y las ciudades experimentaron un crecimiento inusitado, del cual Cuenca es óptimo ejemplo. Como cabeza de Mesta dispuso de una economía boyante fundamentada en la ganadería lanar y en la industria pañera, que le permitió alcanzar los 16.000 habitantes (TROITIÑO VINUESA, 1994). Por ello, hicieron falta la construcción de nuevas infraestructuras no sólo en las ciudades, sino también para comunicar a éstas con villas, aldeas y otras unidades de población, dominar el territorio, explotarlo y defenderlo. Si la plata americana financió estos hechos, es lícito apoyarnos en la fecha de 1492, que marca la llegada de Cristóbal Colón al Nuevo mundo, para señalar el comienzo de los siglos modernos.

No obstante, la conformación de los estados modernos es algo que se viene advirtiendo desde unos pocos años antes en Castilla y otros más anteriores en Aragón. Y de hecho las infraestructuras materiales se levantan con anterioridad, paralelas al desarrollo de las instituciones del nuevo Estado. Si de cultura material se trata, y la arquitectura es el elemento más complejo de las sociedades del pasado (LATORRE, 1996), entonces habría que tomar la fecha de 1479, en la que las Cortes de Toledo, convocadas por los Reyes Católicos, decretaron la construcción de edificios municipales adecuados a la representación y a las necesidades públicas: es decir, las Casas de los Corregidores, las Casas Consistoriales, las Cárceles, las Carnicerías y los Pósitos (YARZA LUACES, 1993). Fue el arranque del que partió el desarrollo de las ciudades de la Modernid en Castilla, basado en una conciencia nueva o más intensa de lo público, que también era responsabilidad del Rey.

Sin embargo, no se trata tanto de buscar una fecha fetiche. Por otro lado, las fronteras de la cultura material entre el Medioevo y la Modernidad no son nada claras, como la de todos los estancos temporales del saber arqueológico. Por ejemplo, los solares en el que se desarrollan las viviendas de los S. XVIII puede ser el mismo que las casas del S. XIV, e incluso puede que en la centuria de 1700 esté aprovechando parte de las estructuras de la de 1300 (QUIRÓS y BENGOETXEA, 2011). Como veremos, buena prueba de esto es el edificio ya comentado de Obispo Valero 10. En frecuente encontrar, en contextos del S. XVI, fragmentos esmaltados de cerámica decorados en azul con tipos que también se dan en la centuria de 1300 . Por tanto, no caigamos tampoco en el fetichismo del objeto, pues el estudio de la cultura material del periodo de transición tiene que saber detectar significados que conforman la mentalidad y las condiciones de la nueva sociedad enmarcada cronológicamente en la Edad Moderna.

Al igual que los eclesiásticos, muchos de los nuevos edificios institucionales que se levantan a lo largo del S. XVI tienen en común el uso de una potente estereotomía que se expresará en bóvedas estrelladas primero -con combinaciones de nervios nunca antes vistas -, para montar soluciones más clásicas después. En su adopción y posterior evolución influyeron decisivamente aspectos sociales y mentales muy concretos, que había en las sociedades castellanas y aragonesas del S. XV. A mediados de la centuria de 1400, la cantería no era la práctica más extendida en la construcción suntuosa o monumental de las 
Coronas de Castilla y Aragón. No se puede simplificar con el argumento de que el modo de construir mudéjar salía más barato por el uso de materiales económicos como el ladrillo. En realidad, lo que hay que afirmar es que esta industria constructiva era mucho más competitiva, pues el moro de paz-nomenclatura con la que se conocía también al mudéjar- permitía una construcción de calidad en un tiempo más célere. La consecuencia de ello es que la experimentación en bóvedas de crucería en Castilla y Aragón parecía congelada en los primeros años del S. XIV y no es de extrañar que apenas hubiera maestros que dominaban ese arte. Es muy revelador que el arzobispo D. Juan de Cerezuela (1434-1442) tuviera que llamar a un maestro del Norte Europa como Hanequim de Bruselas para la construcción de la Capilla de Álvaro de Luna en la catedral toledana (GÓMEZ, 1998).

Ahora bien, no se trata de una simple competición por un gusto arquitectónico. Hay un significado detrás de este cambio y debemos buscarlo en el deseo de Fernando e Isabel de renovar los reinos de Castilla y Aragón, algo que, en cierto modo, también le estaban pidiendo sus súbditos. Los habitantes de la Península por entonces tenían la fama en Europa de ser malos cristianos o cristianos nuevos. No sólo se veía con malos ojos la presencia de los musulmanes durante siete siglos en la Península, sino que además tampoco se comprendía la relativa tolerancia con la que todavía se convivía con mudéjares y judíos. Sin duda, las altas jerarquías de la Iglesia se encontraban incómodas con esta imagen que sus feligreses tenían en otros reinos de la Cristiandad. Las iglesias gótico-mudéjares con decoración de yeserías en realidad recordaban a sinagogas y palacios nazaríes. Por ello, la Iglesia se puso manos a la obra no sólo excitando el antisemitismo y presionando a Isabel y a Fernando a instaurar la Inquisición junto a las expulsiones de los infieles de sus dominios, sino también renovando hasta la imagen que proyectaba la arquitectura de sus lugares de culto. Se comprende, pues, que se tratara de reproducir el lenguaje tectónico y decorativo del gótico de las regiones francesas, flamencas y alemanas, primero y el renacentista después procedente de Italia. Era allí donde estaban los mejores cristianos, los viejos y puros. Así pues, edificios como San Juan de los Reyes en Toledo debemos entenderlos también como el manifiesto de una sociedad que no sólo demandaba la paz y prosperidad que le negaban los enfrentamientos entre reyes y nobles, sino también una fe más "limpia".

No obstante, el mudéjar todavía daría muchos coletazos y sus técnicas pervivirían muchos años después. La introducción de los nuevos conocimientos técnicos fue gradual como todos los periodos de transición. El de la Arqueología Medieval y Post-medieval deberíamos situarlo entre los años anteriores a 1470 y los inmediatamente posteriores -muy inmediatamente posteriores- a 1492. Pero, insistimos en que lo más importante son los significados. Y éstos no son otros que los ya dichos: la necesidad de mostrarse como buenos cristianos y la toma de conciencia de lo público bajo la protección real. Esos dos factores definirán buena parte de lo que serán las mentalidades de las sociedades de Castilla y Aragón entre los S. XVI, XVII y XVIII.

Quizá una temprana manifestación arquitectónica fue en Cuenca la construcción de la girola en 1480 (fase VI de la catedral). Pero la bóveda de crucería triunfaría y se convertiría en el lenguaje tectónico habitual a partir la llegada de los hermanos Albiz a la zona, canteros vizcaínos que introducen las bóvedas de tipo francés en nuestra ciudad con las obras del Convento de San Pablo y la Capilla de los Apóstoles en la Catedral y se extenderían por toda la diócesis llegando a puntos como Uclés, Garcinarro o Carrascosa (MUÑOZ y DOMÍNGUEZ-SOLERA, 2012).

Pero a la vez que se constituían nuevas expresiones monumentales, la sociedad moderna de Cuenca también se caracteriza por el olvido de los símbolos medievales tan característicos como el alcázar y las murallas. Respecto a estas últimas, fueron víctimas del crecimiento de la población, pues la solución cuando falto solar para construir fue aprovechar el adarve de la muralla, para después saltarla literalmente, ya que se utilizó 


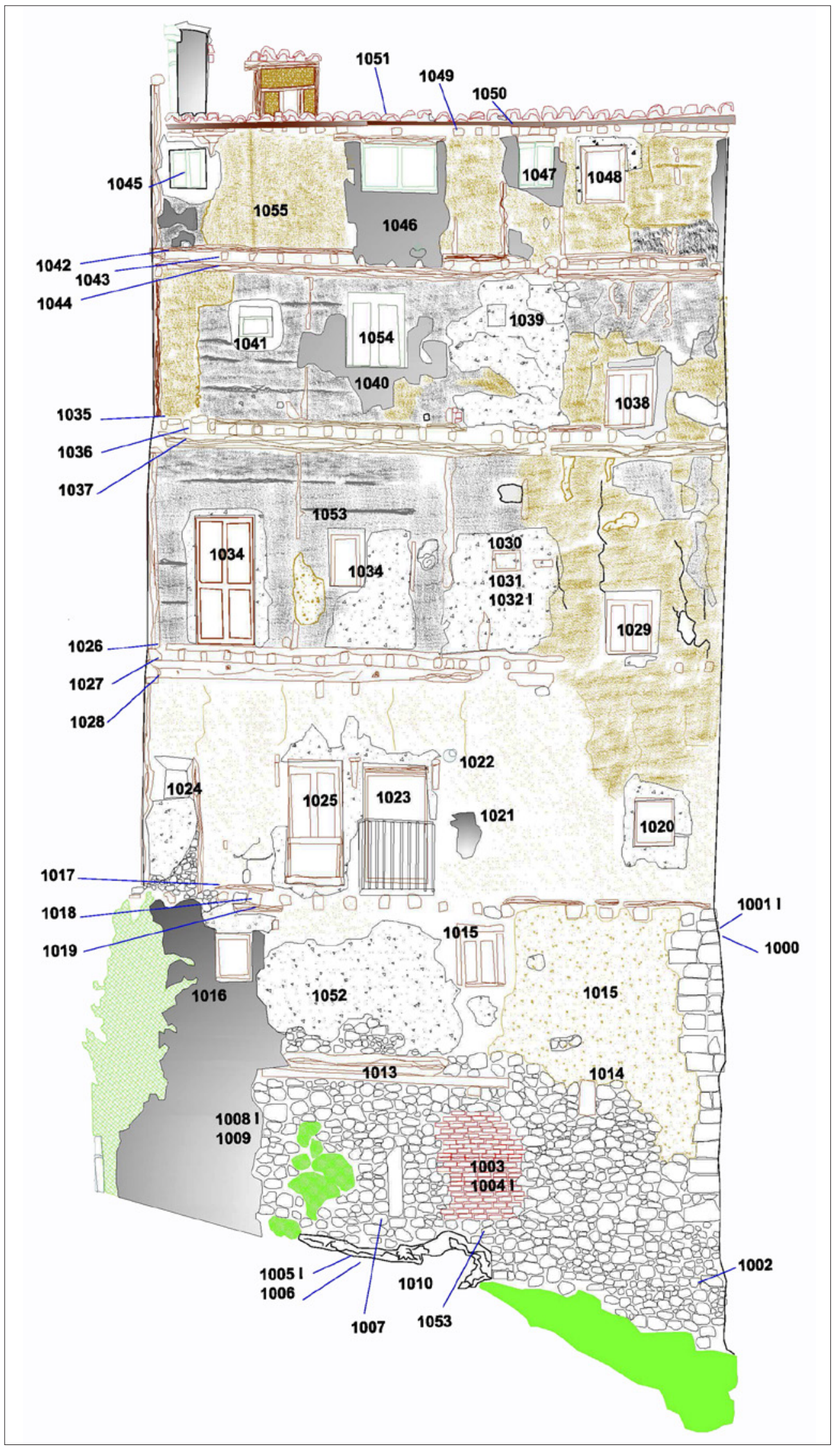

Fig. 6. Individualización Estratigráfica de la fachada del edificio de la calle San Juan 48 con la sillería de UEM 1000, que podría pertenecer a los últimos años de la Edad Media. 
su paramento externo como apoyo a nuevos módulos de edificación. Son, en definitiva, las casas colgadas que ocultaron los lienzos defensivos de nuestra ciudad, que ya han sido ampliamente tratados desde muchos puntos de vista (MUÑOZ y DOMÍNGUEZ-SOLERA, 2011). Es el caso del edificio de San Juan 48, cuya fachada fue estudiada durante los controles arqueológicos del año 2013. La estratigrafía muraria identificada y caracterizada reveló una temprana fase que podría ubicarse en los últimos años del S. XV o primeros del S. XVI, lo cual nos da un margen cronológico de destrucción de la parte del trazado de la cerca urbana, que antaño ocupaba también este solar.

\section{Sobre el Puente de San Pablo y el Acueducto}

En cuanto a las infraestructuras urbanas, hemos realizado un estudio de los muros que contuvieron la Cuesta de las Casas Colgadas y que están directamente relacionados con la construcción del Puente de San Pablo hacia 1520 por parte del maestro Francisco de Luna (ROKISKI LÁZARO, 1985). Pero el gran proyecto fue la construcción del Acueducto por parte de los fontaneros Juan y Rodrigo Vélez y el maestro de cantería de Juan Torollo, en un sorprendente tiempo record que va desde 1531 hasta 1532 (DOMÍNGUEZ-SOLERA y MUÑOZ, 2012). Aquí sólo vamos a tratar el tramo de canalizaciones encontrado bajo la Plaza de la Merced durante los trabajos arqueológicos del Seminario de San Julián en el año 2013.

Se trata de un túnel subterráneo de aproximadamente 60 metros de longitud, unos dos metros de altura y por algo más de medio metro de ancho en algunos puntos, excavado casi completamente en la caliza natural, con un canal en su parte inferior. El canal contiene una conducción de arcaduces empalmados en dirección al Seminario. Sabemos que es una traída de aguas por este último dato: porque la embocadura menor de un arcaduz empalma con la mayor del siguiente, orientándose todos hacia el Seminario y no al contrario.
Los tramos no excavados en roca en su parte superior se cubren con grandes lajas de caliza talladas con puntero romo, mampostería y ladrillo.

Aunque la tubería que ha de pasar por él para llevar el agua sólo tiene unos $20 \mathrm{~cm}$. de ancho como máximo, se excava un túnel transitable (200 x 50-60 cm. aprox.) para poder solucionar roturas, atascos, etc. Para el mantenimiento del mismo. La tubería se hace pasar por un canal excavado en el suelo y, en la tierra que protege los tubos de arcaduz, tenemos la prueba de las reparaciones. Tal consiste en trozos de arcaduces viejos y rotos que fueron sustituidos por los presentes. Los operarios accederían, con los arcaduces a reponer, con masa de cal y con herramientas por el túnel hasta el punto dañado y trabajarían cómodamente por la altura de la galería, sin pisar las tuberías al poder andar por la piedra de ambos lados del canal del suelo.

\section{Las Cárceles Eclesiásticas y Civiles}

En cuanto a los edificios de uso municipal de la ciudad moderna de Cuenca hay que destacar el gran Patrimonio carcelario que conserva. Ello se explica por existir lo que hoy llamaríamos dos competencias jurisdiccionales diferentes: la eclesiástica de la Inquisición y la real de los corregidores. Respecto a la primera podemos decir que obviamente es una consecuencia material del propio estado moderno con su "unificación religiosa" en Castilla y Aragón. Pero ambas son testimonio de la falta de medios para dotarse de una sede definitiva desde la instauración de sus competencias. La cárcel de la Inquisición pasó por el Palacio Episcopal hasta que el Obispo Diego Ramírez de Villaescusa llegó a un acuerdo de traslado en 1525 pero hasta 1530 no podría comenzar las obras del actual patio porticado. No obstante, quedaría todavía como usos del tribunal la parte oriental de la Casa del Obispo. Sin embargo, no sería hasta 1583 cuando se produje el traslado al nuevo edificio del Tribunal en la antigua sede del Alcázar Real (SOLIS, HUELAMO, COLL, 1990, p. 
97). Entre medias el tribunal también ocupó el edificio actual del Museo Arqueológico, la antigua Casa del Curato y hasta 1574 no se trasladarían los presos desde los Cuartos de San Julián (IBÁÑ̃EZ MARTíNEZ, 2006), p. 368), ya que el Obispo Quiroga era también Inquisidor General.

La cárcel eclesiástica se asentó unos nueve años en la Casa del Arcediano (calle San Pedro 40), que también ha sido objeto de intervención arqueológica por nuestra parte. En su lectura estratigráfica definimos una fachada noble que combinaba mampostería concertada vista con la sillería en esquina y otros elementos nobles de cantería como portada y vanos. Ello es más trascendente de lo que parece en cuanto a la acción de restauración se refiere, puesto que posteriormente se han añadido en este edificio otras muchas capas de enlucido que originalmente no tenían. El aparato carcelario se encontraba también en la trasera del edificio que estaría hoy ocupado por parte de la Ronda de Julián Romero a la altura del Cristo del Pasadizo y la plazoleta adyacente que hoy es un mirador.

Respecto a la cárcel municipal ésta terminó ubicándose en el edificio de la Casa del Corregidor. El actual edificio integra tanto el Palacio por el que se entra desde la calle Alfonso VIII, como la cárcel trasera de dos volúmenes que mira a la hoz del Río Huécar. En principio, quedaba ubicada en el Barrio del Alcázar y estuvo allí en uso hasta 1541. A partir de esa fecha se trasladó a la calle de la Correría, porque el Concejo estimaba necesaria la construcción de una nueva prisión, más amplia, para el buen gobierno de la ciudad. La obra se encargará al maestro de carpintería Cebrián de León el Viejo (que tuvo gran responsabilidad en las trazas del edificio) y a los maestros de cantería Sebastián de Arnani, Francisco Vélez, Francisco de Calahorra, Juanes de Mendizábal el Mozo y Martín de Mendizábal el Viejo.

La lectura estratigráfica practicada en el año 2013-2014 demostró que los restos del "prison" que se advierte en la vista de Wyngaerde de 1565 estaban embutidos en el edificio actual. Los ambientes y estructuras de este primer edificio han pasado desapercibidos hasta el año 2011, en que se halló un conjunto de celdas que permanecían tapiadas. Se organizaban en tres crujías y además se identificó el patio que enlosó Martín de Mendizábal el Viejo en 1540 (IBÁÑ̃EZ MARTíNEZ, 2006: 222) en la planta más baja del edificio. Ese mismo año se tasaron unos pilares de fuente por parte de Pedro de Albiz, creemos que los mismos se pueden identificar con los sillares inferiores que se ven en la letrina del S. XVIII. Es decir, es muy posible que la misma se edificara sobre la caja donde se contenía el agua. Esta entraría por un arcaduz que todavía existe y que conectaría con las conducciones que bajaban por la calle Correría, hoy de Alfonso VIII. No obstante, pensamos que sólo una excavación arqueológica más intensa fuera del edificio acabaría por confirmar todos estos elocuentes indicios.

También destacamos que lo que supusimos como otra posible antigua letrina o espacio vertical no identificado, correspondía a un patio o pozo de luces y ventilación. En las celdas denominadas como unidades funcionales 103 y 107 se abrirían unas ventanas sobre el Cuerpo de Fábrica 23 -supuestamente con rejas- que proporcionarían escasa luz y corrientes de aire, que contribuirían a hacer más respirable la cargada atmosfera de estas partes del presidio.

\section{La Capilla del Espíritu Santo y el Nuevo Claustro Catedralicio}

Respecto a la introducción del movimiento cultural del Renacimiento en Cuenca y todo lo que intelectualmente supone sobre la cultura material, es una explicación muy compleja que aquí no podemos desarrollar. Pero, por formularla de una manera sencilla y muy general, si la introducción de gótico hispano-flamenco significa una manifestación de la limpieza de fe, la adopción de la estética romana significa incorporarse a las corrientes culturales más punteras que por entonces triunfaban en Europa. De hecho, será utilizada en cierto modo por la monarquía de Felipe II, no sólo para imprimir monumentalidad a 


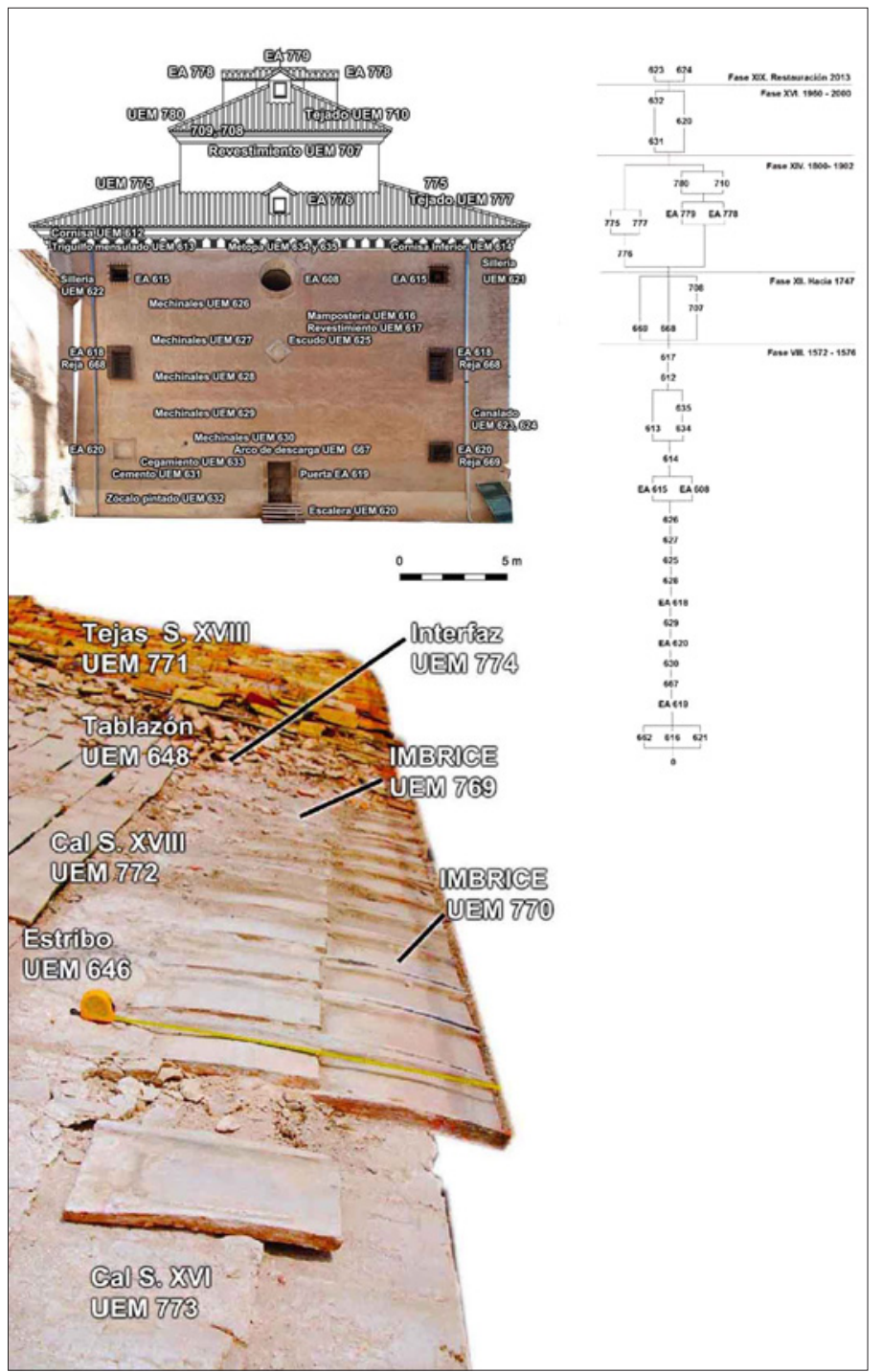

Fig.7. Análisis estratigráfico del cuerpo de fábrica 61 en la Capilla del Espíritu Santo e individualización en UEM de parte de la cubierta donde se aprecian los ímbrices dispuestos por Juan Andrea Rodi.

chará el material de derribo del antiguo claustro medieval, para conformar muros de mampostería recubiertos de estuco. Lo único que conocemos de los orígenes de Rodi es que era milanés y su trabajo en la gran cantera del Escorial no es algo comprobado, por lo que su contacto con Juan de Herrera y el denominado modo "purista" -según unos- o "clasicista" -según otros- no se daría hasta su intervención en el claustro catedralicio conquense, en un periodo posterior a la finalización de la Capilla del Espíritu Santo en 1576 y que también ejecutó Rodi en sus primeras fases. $\mathrm{Ni}$ siquiera el austero interior blanco del pequeño templo funerario de los Hurtado de Mendoza puede relacionarse con seguridad con los diseños escurialenses, pues estos tipos están presentes en

su poder, sino también para acompañar al movimiento de la Contrarreforma. Lógicamente nos referimos al reportorio arquitectónico nacido de la construcción del Monasterio del Escorial. Una consecuencia directa de esto, sería el encargo a Juan de Herrera para realizar las trazas del claustro de la propia Catedral conquense, del cual ya nos hemos ocupado en anteriores ocasiones (MUÑOZ y SOLERA, 2010). Pero inmediatamente antes de su alumbramiento, el milanés Juan Andrea Rodi introdujo el más genuino renacimiento italiano en una de las obras más singulares de la corona de Castilla: la misma Capilla del Espíritu Santo.

Fue una obra que se ejecutó con relativa rapidez, ya que como hemos visto se aprove- algunos ejemplos italianos el templo de San Eligio degli Orefici en Roma. Posiblemente, la inspiración de Juan Andrea Rodi para este edificio debió ser la edilicia que vio en su juventud en su Italia natal (habitus y elección cultural). Hay además dos elementos que nos relaciona más firmemente a Rodi con los usos arquitectónicos de Italia: nos referimos a las costillas en ladrillo del extradós de la cúpula de la Capilla del Espíritu Santo y a los restos de su tejado del S. XVI.

Es cierto que soluciones con costillas cruzadas aparecen en el Tratado de Alonso de Vandelvira, donde una de las páginas muestra una cúpula para una capilla redonda por cruceros. Era algo que debía ser ya muy conocido por los maestros de cantería castellanos de 
entonces. Sin embargo, el uso de ladrillo recuerda poderosamente a fórmulas italianas como a las que recurrió Brunelleschi para la cúpula de Santa María de las Flores, donde el versátil ladrillo permitió anclajes en espina de pez que favorecieron la consistencia de la misma.

Nos han sorprendido las medidas del ladrillo empleado, que difiere con el que utilizó el propio Rodi en la primera campaña del claustro catedralicio. En la Capilla del Espíritu Santo el módulo es diferente: se han apuntado ya unas dimensiones de $26 \times 14 \times 5 \mathrm{~cm}$. que contrastan con los $24 \times 20 \times 4 \mathrm{~cm}$ que apareja la UEM 1501. Esta unidad se corresponde con los ladrillos que se acoplan en la bóveda de arista de las pandas Norte y Oeste del Claustro Catedralicio. De por sí, la producción cerámica para la construcción en Cuenca presenta un panorama muy activo, pues entre otras muchas cosas debía responder todos los años a las demandas que planteaba el mantenimiento del Acueducto, cuyas conducciones en buena parte eran los tradicionales arcaduces.

Respecto a los ladrillos de la cúpula que aquí analizamos, si bien podrían ser objeto de un encargo muy particular con unas medidas que se salían de lo común, debemos también empezar a valorar que las medidas estaban en función del destino final para el que se fabricaba un determinado elemento latericio. En los Veintiuno Libros de los Ingenios y las Maquinas de Pedro Juan de Lastanosa, escrito en la segunda mitad del S. XVI, se proponen una serie de módulos que se adecuaban al uso que se les iba dar.

De hecho, sólo desde una petición específica podemos entender el encargo del segundo elemento italiano de los ímbrices -o imbrici en italiano-, que conformaron el tejado original de este este edificio, localizados en las UEM 769 y 770; lo cual es un elocuente ejemplo de la versatilidad y capacidad de lo que hoy entenderíamos por "industria de los materiales de construcción" en la Cuenca de la II mitad de la centuria de 1500. Los ímbrices en cuestión presentan dos tipos: uno plano y otro curvo. No sabemos de ningún paralelo en la geografía nacional durante el renacimiento, pero sí de muchos en Italia, donde son utilizados hasta como soporte de pintura al fresco (TAPETE, 2009: 10-18). De hecho son mencionados en el Tratado de Alberti De Re Aedificatoria (ALBERTI, 2007: 159-160). Lastanosa también alude al tipo de tejas planas.

Respecto a los ímbrices curvos hemos observado que se adaptan muy bien a la línea curva de los exteriores de cúpulas como la mencionada de la Catedral de Florencia, Santa María de las Flores o la Sacristía Nueva de la Basílica de San Lorenzo en la misma ciudad, diseñada por Michelangello Buonarroti. Su posición en la hilada más exterior del tejado de la Capilla del Espíritu Santo posiblemente responde a la necesidad de dirigir las aguas pluviales con un tiro hacia abajo vertical, protegiendo no solo las fachadas exteriores, sino también más eficazmente las cornisas.

En definitiva, la combinación de planta, interior, estructura de la cúpula y el cerramiento con ímbrices hicieron una construcción extraña al renacimiento de bóvedas de crucería, que arquitectos y escultores como los hermanos Albiz o Esteban Jamete habían desarrollado en Cuenca. De hecho, el diseño de Andrea Rodi parece una trasposición de un edificio italiano del Cinquecento italiano y posiblemente fue algo buscado por este maestro, pues hay mucha diferencia visual entre las construcciones rematadas con la teja tradicional árabe y los ímbrices de tradición itálica.

\section{El Siglo de Hierro y el Siglo de la Ilustración}

En los tiempos de Juan Andrea Rodi, aunque todavía se permitía una boyante construcción, los gastos del imperio ocasionaron bancarrotas que, unido a malas cosechas y hambrunas, no hicieron más que empobrecer a las clases populares. La situación se agrava aún más en la la mitad del S. XVII. Las cifras son elocuentes en Cuenca: de tener los dichos 16.000 habitantes, en 1646 la población desciende a sólo 4.000 habitantes. Las cifras 
que hubo en el Renacimiento no volverán a alcanzarse hasta ya el siglo XX (TROITIÑO, 1994: 207-221).

Ante una monarquía endeudada por empresas exteriores y unas clases nobles y bajas empobrecidas, el clero expandía su economía, puesto que en tiempos difíciles las necesidades de piedad eran mayores. Se aprovechó de la bajada de precios en solares para adquirir propiedades sobre los que se levantaban fundaciones monásticas, que también eran sufragadas por la nobleza que podía permitírselo. En Cuenca, tenemos constancia de una industria de la construcción eclesiástica ágil en la II mitad del S. XVII, la misma que finalizó una campaña en la iglesia de San Andrés según la dirección de Felipe Crespo (MUÑOZ y DOMÍNGUEZ SOLERA, 2014). Sin embargo, no podemos medir sin sesgo el alcance de la conversión en ciudad convento de la capital conquense en el "Siglo de Hierro", puesto que el bombardeo inglés de 1706 -durante la Guerra de Sucesión- dejó arruinada gran parte de la ciudad y fue tan intenso que tuvieron que reconstruirse casi todas las iglesias durante el S. XVIII. El aspecto actual de los templos de San Pedro, San Felipe Neri, San Antón, el Santuario de las Angustias, Santa Cruz, etc. así lo certifica, pero son también el testigo de una pujante industria de la construcción. De la monumentalidad alcanzada es testimonio del mismo modo el pro- pio edificio del Seminario de San Julián. En la intervención arqueológica pudimos documentar interesantes elementos que nos hablan del modo de construir de este siglo.

\section{El Seminario de San Julián}

El estudio pormenorizado de sus cámaras bufas es indicativo de la magnitud que supuso su obra, pues se tuvieron que arrasar las estructuras precedentes hasta la roca madre.

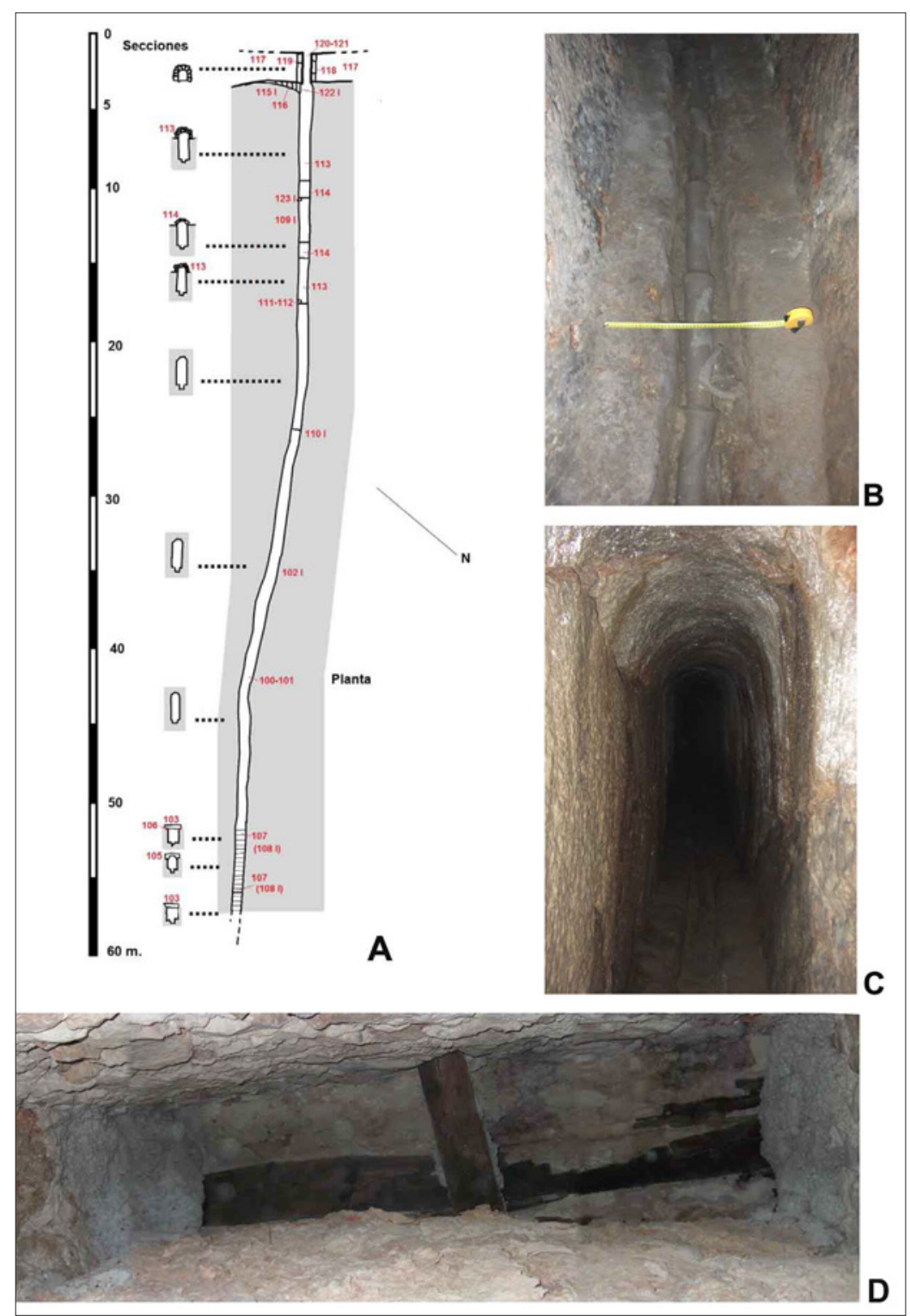

Fig. 8. A. Plano del acueducto del S. XVI cuyo tramo va desde el Seminario de San Julián hasta la Plaza Mayor. B. Detalle de los arcaduces conservados en el canal inferior, C. Sección del acueducto. D. Armadura para encofrado de bóveda de yeso fosilizada en las cámaras bufas del Seminario de San Julián, S. XVIII. 
Pero no sólo eso: se picó la roca hasta una cota bajísima con el fin de obtener más espacio útil. Por otro lado, encontramos restos fosilizados del proceso constructivo que se encuentran en una de las cámaras, donde se han conservado buena parte del sistema de encerchado, que se utilizaba para la construcción de estas bóvedas de mampuesto que datarían de mediados del S. XVII.

Aunque es un tema que estamos estudiando todavía, en toda la tratadística conservada no hemos encontrado rastro de este sistema que sujetaba las tablas para encofrar (UEM 247) mediante otro tímpano encofrado previamente (UEM 253), sostenido a su vez por una viga cargadora de madera (UEM 252). Esto no era más que una solución de obra que lógicamente no se mantenía permanente. Que se nos haya conservado seguramente responde al carácter cerrado que tenía esta cámara bufa.

Pero lo interesante, es que otros tímpanos encofrados - como las UEM 246 y 255 - se convirtieron en estructuras permanentes. En realidad, muestran la versatilidad constructiva que presenta este S. XVIII, que en cierto modo podríamos entenderlo como el "siglo del albañil" -en cuanto a construcción monumental se refiere-. Recordemos que en esta centuria Juan de Villanueva escribirá su célebre Arte de la Albañilería. Es decir: la técnica de un viejo oficio consagrado a una categoría mayor.

Pero volviendo a la descripción de las infraestructuras del Seminario: las cámaras bufas evitaban humedades en las paredes de las estancias que daban a la parte de Mangana, donde discurren importantes vías de agua natural por filtración a través de la roca geológica. Además, comprobamos que el mencionado rebaje para las plantas que se cuelgan en la hoz se hace con la previsión de evitar acumulación de humedad, dotando a la cámara bufa de algunas excavaciones o perforaciones transversales a ella. El agua acumulada en el fondo de la cámara bufa discurriría hacia el centro de los claustros y se perdería por un sistema desconocido de momento hacia la parte del edificio que da a la Hoz del Júcar.
Este modo de construir también tuvo su reflejo en la construcción pública, pues el carácter reformista de los reyes ilustrados, favorecieron la solución de las carencias físicas y materiales que tenían las ciudades del Reino. En Cuenca ya hemos tratado en otras ocasiones los casos de los empedrados (MILLÁN y MUÑOZ, 2007) del Ayuntamiento y del Pósito o del Almudí (MUÑOZ y DOMíNGUEZ-SOLERA, 2013). Ahora nos ocuparemos únicamente de la reforma de la reforma de Casa del Corregidor y su cárcel asociada que como vimos se fundó en el S. XVI.

\section{La Reforma de la Casa del Corre- gidor en la centuria de 1700}

En 1762, por iniciativa del corregidor Juan Núñez del Nero y Portocarrero, tras pedir éste permiso al rey -que era Carlos III-, se inicia una nueva e intensa fase de reforma que tenía como objetivo la renovación tanto de la cárcel como de las dependencias del mismo corregidor. El proyecto inicial se tuvo que modificar y el arquitecto José Martín de la Aldehuela presentó unas nuevas trazas y un presupuesto con partidas diferenciadas para demolición, prisión y vivienda del funcionario. Los motines de 1766 retrasaron aún más los trámites para comenzar las labores. Además, se tuvo que pedir ayuda a los pueblos de alrededor, pero el permiso real para ello no llegó hasta 1769. La obra fue sacada a subasta pública y cayó en manos del maestro arquitecto Vicente de Montoya. Algunos de los materiales del antiguo presidio fueron a parar a las tareas de edificación de otros edificios públicos, lo que prueba los graves problemas económicos por los que estaba pasando la urbe (ROKISKI, 1995: 347). Estos años contrastan con la década anterior, en que se terminó el mentado Pósito Almudi entre 1751 y 1753 (ALIOD, 1997: 71-72). Veremos más adelante que tanto fachada como interior del área referente a la vivienda del Corregidor fue muy alterada en el S. XIX. En cuanto a la prisión, ésta no fue la misma que en el S. XVI, pues se cerraron las crujías interiores más profundas, a la vez que se añadían bodegas del edificio adyacente y se rebajó la altura de la cárcel. El antiguo patio 

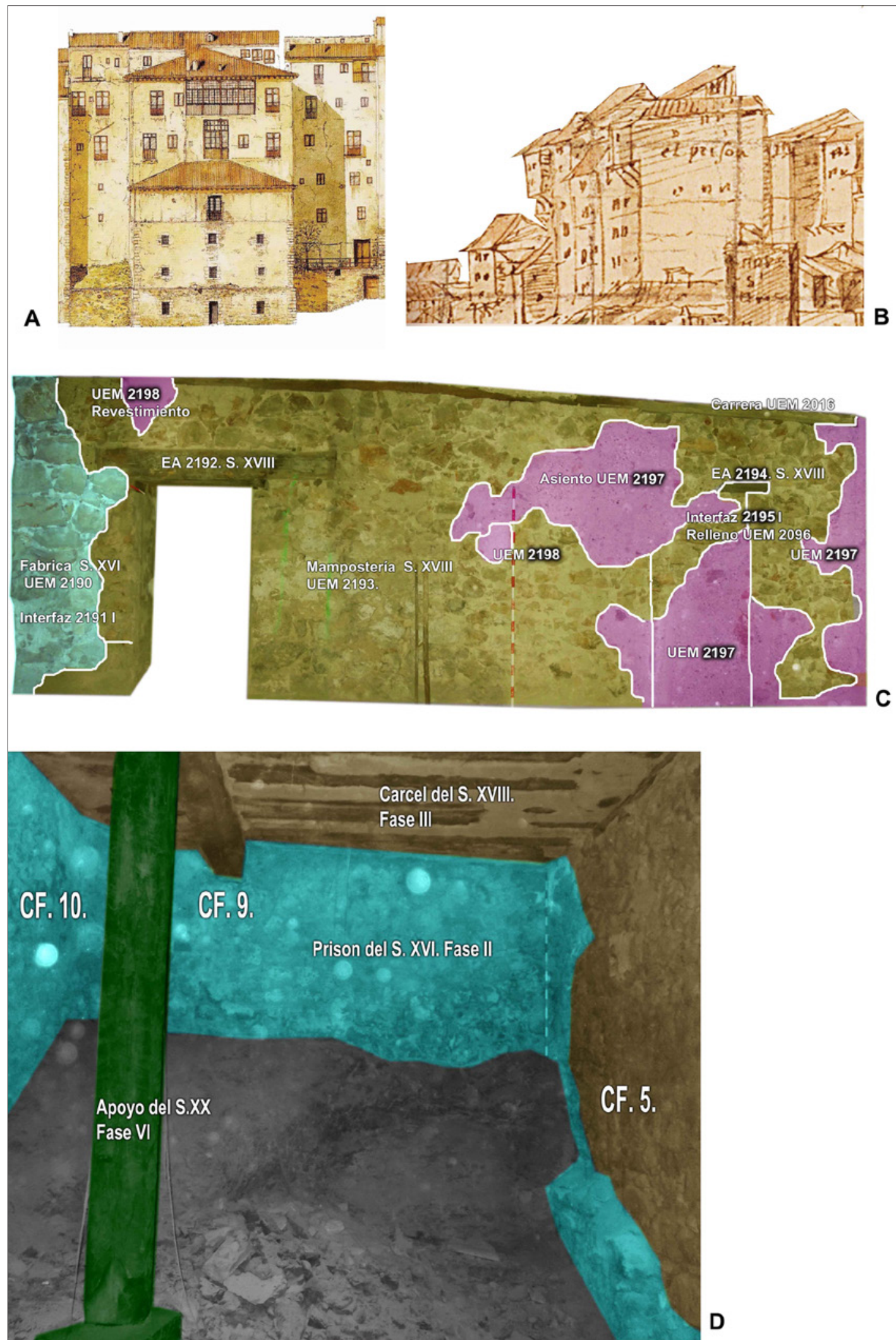

Fig. 9. A. Casa del Corregidor en la actualidad con las ampliaciones del S. XVIII y XIX. B. Casa del Corregidor en la Vista de Cuenca desde la Hoz del Huécar de Wyngaerde (1565). C. Lectura del cuerpo de fábrica 5 en la primera planta donde se aprecian en azul el resto de la Prisión Real del S. XVI. D. Primera planta de la cárcel, donde se advierte también en azul las unidades murarias que pudieron contener el patio central que se menciona en la documentación de la centuria de 1500. 
fue convertido en celdas distribuidas en una planta baja y tres alturas.

Aun así, su capacidad de acoger reclusos aumentó con respecto al edificio que dibujó el flamenco Wyngaerde en la centuria de 1500. Ya vimos cómo descendió la población hasta un tercio debido a las difíciles condiciones que se dieron en las crisis del S. XVII. Pero el incremento del uso de la pena de cárcel fue en progresivo aumento, cosa que se refleja en el desarrollo de las leyes (RAMOS, 2008) y también elocuentemente en la materialidad arquitectónica de la Casa del Corregidor. Esta tendencia se va a mantener en el S. XIX, periodo en el que sigue en uso este edificio carcelario, aunque bajo batuta del estado liberal-burgués. Entramos ya en la esfera de la Arqueología del periodo contemporáneo que se conoce genéricamente como "Arqueología Industrial”, siendo esta cárcel el escenario para continuar nuestro discurso.

\section{El Periodo Contemporáneo o "Industrial" en la Casa del Corregidor}

El estado liberal-burgués, que sobre todo se consolida a partir de la subida al trono de Isabel II, dejó aislada finalmente a la Provincia de Cuenca: el ferrocarril Madrid-Alicante (1843-1862) marginó la ciudad, pues primó la conexión con Levante, enlazando por Albacete. De este modo, se daba satisfacción al Marqués de Salamanca, que tenía sus tierras por donde pasaba el trazado de las vías. El tren no llegaría hasta 1883 y la conexión con Valencia no se construiría hasta 1947. No hubo burguesía industrial y la falta de inversión en el campo, condicionó un modelo arcaico de economía agraria (LÓPEZ VILLAVERDE, 2006). Se comprende, pues, que la situación de las infraestructuras estatales, ya en entredicho en provincias bien comunicadas, adquiriesen situaciones de precariedad sorprendentes a nuestros ojos.

Concretamente, nos referimos al Pleno del Ayuntamiento de 1844 en que se comisiona a caballeros obreros para colocar la escuela primaria en la Casa Pretoria, así como la Casa del Maestro y su familia. Es decir: en la misma Casa del Corregidor donde además están o estarán los Juzgados y la Cárcel. Ubicadas todas estas funciones en un mismo edificio, se demuestra muy poca capacidad para adquirir o construir inmuebles nuevos por parte de la administración conquense. Los niños se mantendrían en el edificio hasta la Guerra Civil (NAVARRO GARCÍA, 1998), según el testimonio de testigos todavía vivos. Concretamente y por ejemplo María del Socorro Olarieta, nacida en 1931. Además, está el testimonio de la puerta de la celda UF 103, donde se ha conservado la queja de unos niños escrita a lápiz, que son encerrados por jugar a la pelota con los presos.

De las condiciones de los reclusos da buena cuenta la excavación en área de las celdas denominadas UF 236 y 237. Corresponden a dos antiguas bodegas abovedadas en ladrillo que se incorporaron a la cárcel en la centuria anterior. La estancia estudiada ni tuvo ventanas ni huellas de haberlas tenido nunca. Este hecho, puesto en relación con la presencia de pequeñas acumulaciones de carbón en los extremos de la estancia y con las huellas verticales de hollín en las paredes, informan sobre la forma de obtener iluminación y calor en el interior de las celdas: dado que una hoguera grande habría llenado de humo el interior de la estancia, intoxicando a los ocupantes, sólo se podían encender pequeños hogares junto a las paredes. Para iluminar el espacio también se colocarían astillas en las grietas de las paredes de mampostería, como denotan las huellas de hollín verticales en ellas. Los tipos cerámicos hallados son recipientes de distintas tipologías: elementos de uso común, vajillas típicas desde plena Edad Moderna hasta ciertos platos decorados más propios de finales del XVIII hasta el XIX (pieza AA11-8-459 y 460, por ejemplo). Ello confirma sin margen de duda, que estas unidades funcionales 236 y 237, comenzarían a utilizarse en el siglo de la Ilustración y se tapiarían en el siglo de la revoluciones.

Los juzgados se introdujeron en el palacio de la desaparecida figura del corregidor castellano, añadiendo el volumen trasero que se recrece hacia la Hoz del Huécar, con 


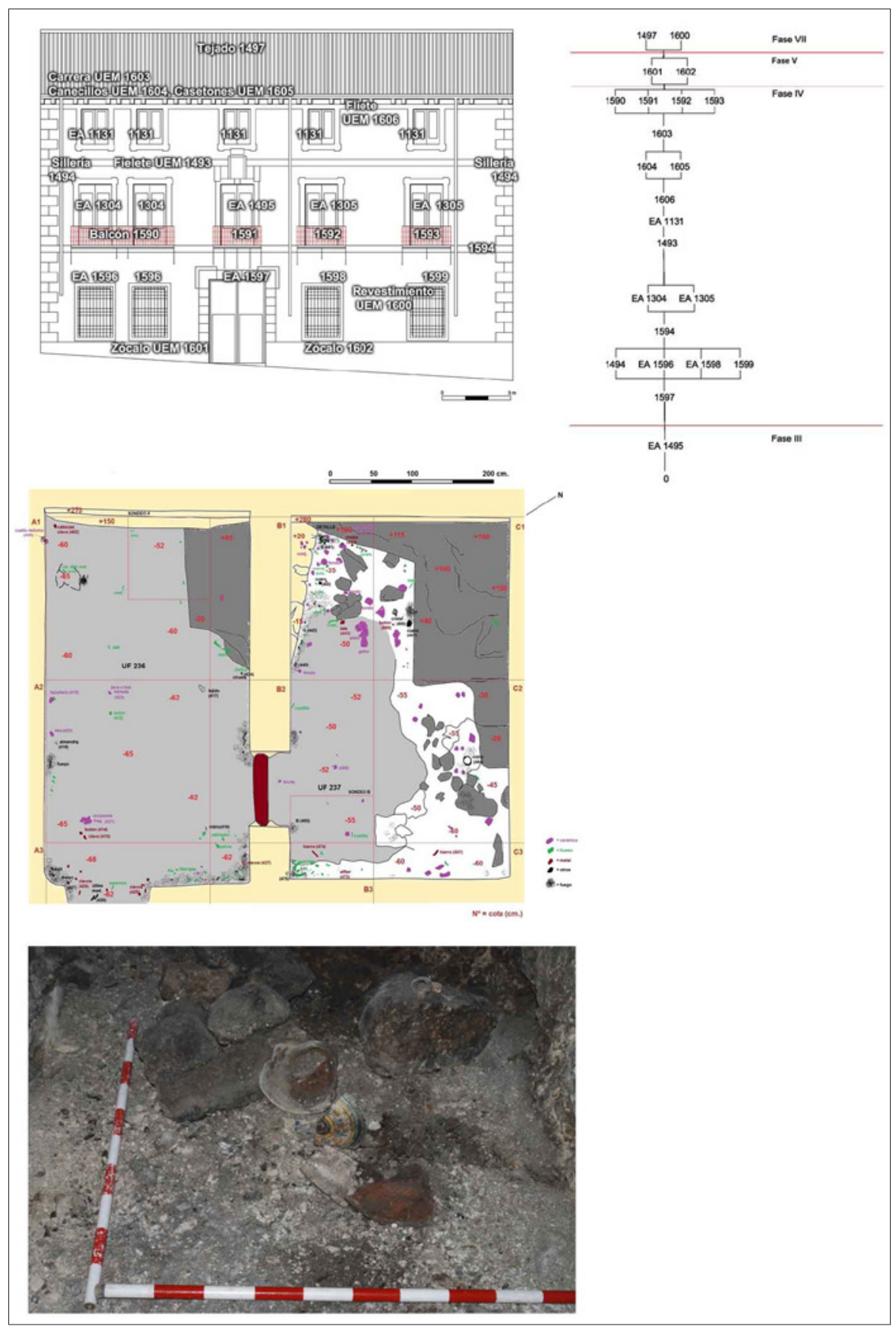

Fig. 10. Arriba

lectura estratigráfica del cuerpo de fábrica 25 de la Casa del Corregidor, que da a la calle de Alfonso VIII, prácticamente fue rehecho a finales del S. XIX o principios del S. XX. En el medio, planta de la excavación de las celdas de las unidades funcionales UF 236 y 237 y, debajo, aspecto de la UF 236 en el momento de su apertura, con cerámicas del S. XVIII y XIX esparcidas por su suelo.

los llamados cuerpos de fábrica 43 y 48. Es entonces cuando se realizan los cierres exteriores de la cuarta planta en los cuerpos de fábrica 1,2 y 3 . Además, se habilita una cuarta planta con las unidades funcionales 238 y 239, que incluye también la reforma de la que denominamos nosotros familiarmente como "Celda de las Bailarinas", por los grafitis allí aparecidos pero que numeramos científicamente como UF 107. Es curioso que los cierres exteriores se resuelvan con pies derechos y cuarteles o rellenos de yeso. Si está tercera planta (cuarta altura) se cerró originalmente en piedra... ¿Dónde fueron a parar las piezas de ese material? ¿Cuál sería la causa de la supresión de ese hipotético cierre pétreo del S. XVIII? Respecto a la fauna hallada, los animales más representados son los de talla mediana. Abunda el ovicáprido, ya sea oveja o cabra. Los animales pequeños, ya sean peces, aves o lagomorfos (liebre o conejo) van detrás en la estadística elaborada. Los bóvidos sólo están representados en puntuales ocasiones. Pero en general, valoramos las condiciones 
de vida en esta celda como privativas: sin luz natural, consumiéndose partes marginales de los animales (mayor representación de partes distales de los miembros que proximales, que son las que menos carne contienen), basuras acumulándose en las esquinas, necesidad de encender pequeñísimas fogatas, mobiliario nulo, ausencia de ventilación... Por eso creemos que estamos ante una celda de castigo o confinamiento.

Volvamos a las obras de los juzgados. En la unidad funcional 301 redescubrimos su envergadura real al demoler tabiques divisores posteriores del S. XX. Era un salón amplio con dos pies derechos de madera y decorados, estilo muy propio del XIX conquense. Entendemos que ésta era la sala principal del Juzgado, de la Audiencia Provincial de Cuenca. También en este periodo se conectaba la Casa del Corregidor con la cárcel mediante la escalera actual de bajada (hoy en cemento, pero el tiro sería el mismo). Es muy posible que hasta ese momento, no existiera esta conexión y, por tanto, el acceso a la prisión se solucionaba desde la Hoz del Río Huécar y, tal vez, por las estructuras de escalera colgadas y condenadas sobre la unidad funcional 106.

Esta reforma incluyó también las columnas de fundición de la unidad funcional 314. Al no existir industria en Cuenca, obligatoriamente tuvieron que ser compradas fuera y traídas por ferrocarril. Por ello pensamos que, por lo menos, las reformas de las plantas superiores habrían de situarse después de 1885, fecha que como hemos indicado significa la llegada de un servicio de trenes a la ciudad.

De igual modo, entra dentro de lo posible que la introducción de las columnas de forja (UEM 2199) fuera pareja a la reforma de la fachada de lo que fuera Casa del Corregidor y que en el XIX ya no lo era. Fijémonos en la unión de los recercados de los vanos de la segunda planta (EA 1131) y la moldura de filete superior (UEM 1606). Son dos elementos que están unidos: la moldura es el propio dintel de las ventanas. Ésta es una solución no conocida en la Edad Moderna y la ponemos en relación con los proyectos publicados por Troitiño
Vinuesa (1995) en el tomo de Arquitectura del Cuenca: El Paisaje Urbano del Casco Antiguo. En la reforma de la fachada y aumento de un piso en la Casa No 3 de la Puerta de Valencia se muestra que su fachada se soluciona en idéntica disposición. Está firmado por el arquitecto Manuel Mateo en 1867 (TROITIÑO, 1995: 105). Ello lo confirma la lectura estratigráfica de la fachada principal de la Casa del Corregidor, ya que hemos observado el uso de bujarda, un instrumento que también es muy raro encontrarlo en cronologías por debajo de 1800 en España.

\section{Sobre la Guerra Civil en Cuenca}

En el último decenio, el interés por la Guerra Civil ha hecho que la Arqueología también se implicase en esta confrontación, que sigue hoy siendo en muchos aspectos traumática para la sociedad española actual. Se le ha dado un perfil científico englobándola dentro de la disciplina conocida como Arqueología del Conflicto (Izquierdo Benito, 2008). Nosotros mismos hemos desarrollado una labor que se ha visto reflejada en el proyecto "Cuenca Subterránea", en el que tratábamos sobre todo la cuestión de los refugios antiaéreos, y en la frustrada empresa poliorcética de fortificar el Cerro del Socorro (PEINADO, DOMÍNGUEZ-SOLERA y MUÑOZ, 2012). En el año 2014 hicimos una pequeña excavación en el reducto sobre el que se asienta la estatua colosal del Sagrado Corazón y en el fortín adyacente de Mirabueno, cara a su futura musealización. En el primero de los puntos se descubrió, como era de prever, puestos de fusil y ametralladora, mientras que en el segundo se definieron las estancias de la torre central y se descubrió una curiosa atarjea de desagüe, aparte de la boca de trinchera que partía desde este puesto hacía el nido de ametralladoras inferior.

Sólo nos queda exponer un elemento que podemos considerar post-industrial, pero que se enmarca dentro de la cultura artística del expresionismo abstracto español, que se conformó en Cuenca durante los años 60 del S. XX. Nos referimos a la excavación del Alfar 
del ceramista Pedro Mercedes, alguien que comenzó su carrera como alfarero tradicional que producía piezas de consumo doméstico, para pasar después a modelarlos como soporte del arte y pasar a nuestra historia reciente como el artista consagrado que es.

\section{El alfar de un artista de la II mitad del S. XX}

Aparte de confirmar que el mismo taller tuvo ese uso desde la época bajomedieval por el repertorio material hallado de esa época y
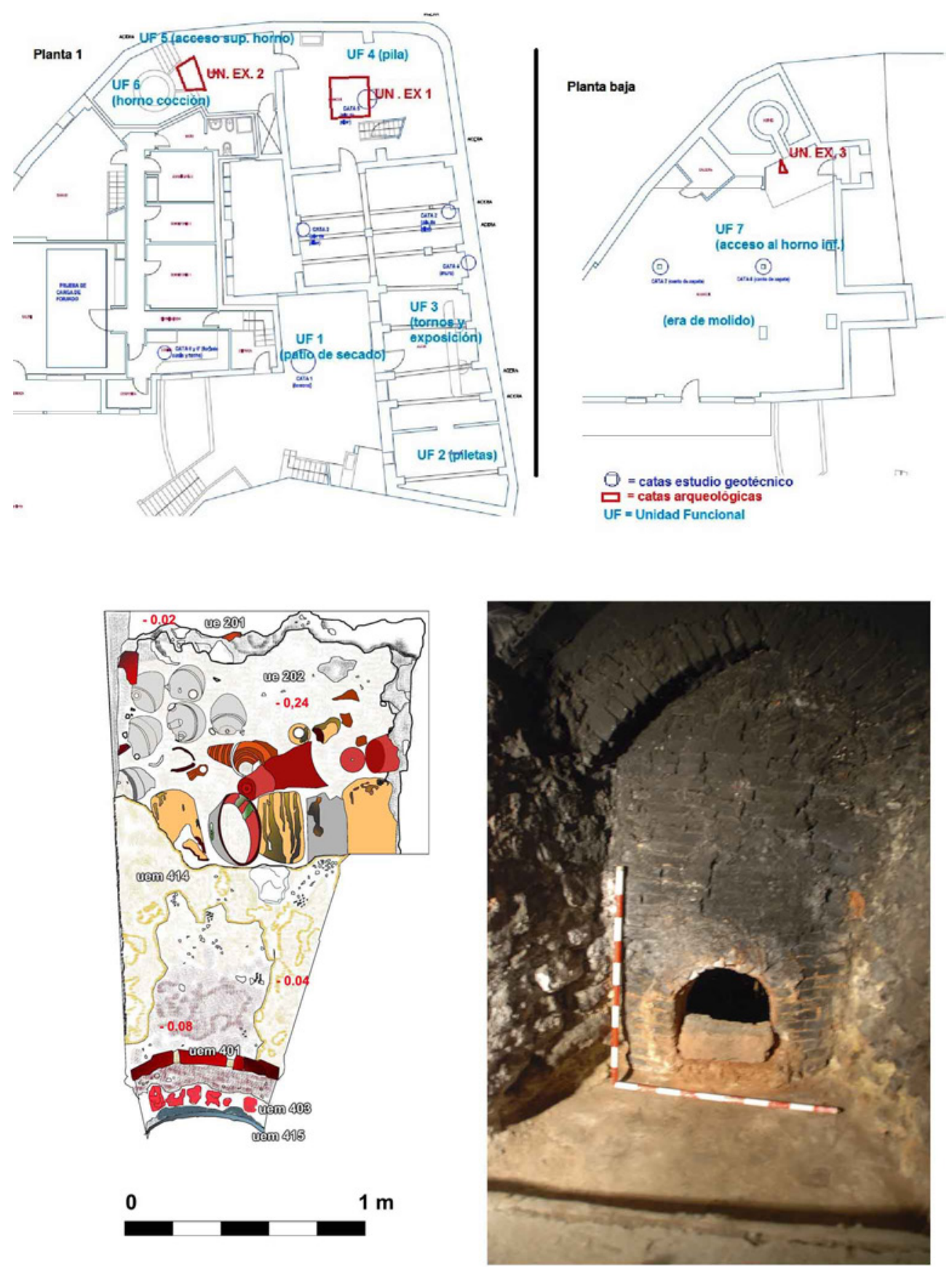

Fig. 11. Alfar de Pedro Mercedes. Arriba planta del edificio con la ubicación de las unidades de excavación. Abajo a la izquierda, planta de la unidad de excavación II y debajo a la derecha, unidad de excavación 3 al pie de la cámara de combustión. 
las subsiguientes, también se hallaron varios sellos de marca de taller que nos remiten al trabajo allí del alfarero Félix Pérez, que tuvo el taller desde finales del XIX hasta la Guerra Civil. José Martínez y su hermano trabajaron también con él a sus órdenes. Según nos cuenta el primero, José Martínez, Félix Pérez fue represaliado en la posguerra y tuvo problemas serios para continuar con su trabajo. Siendo ya un anciano, habiendo adquirido Pedro Mercedes el alfar en 1948, llegó a acogerlo en él para que le ayudase en el trabajo.

De la alfarería de Félix Pérez tenemos restos o testimonios en las unidades funcionales de la 1 a la 9: estarían en funcionamiento ambos hornos, los tornos y las piletas de las UF 2 y 3 existían, según verifica José Martínez, testigo directo. Pedro Mercedes realizó unas pequeñas reformas al principio, según nos cuentan el mentado José Martínez y Tomás Mercedes. El horno más grande no se encendió más allá de 1949 y el horno pequeño, el que hemos analizado, funcionaba con su diámetro máximo.

Se trata de un horno de tiro superior descubierto y con dos cámaras distinguidas: una para la combustión de la leña abajo y otra directamente sobre la primera donde se cargan las piezas de cerámica para su cocción. Son tipologías y sistemas de hornos con precedentes en Mesopotamia y el Mediterráneo desde la Antigüedad (CARO, 2002, pp. 79 y 80). Estos hornos son siempre estructuras circulares altas con ladrillos macizos o adobes enlucidos para retener el calor y se suelen colocar en desniveles del terreno para tener acceso a las dos cámaras, con entradas independientes a distinta altura. Es el caso exacto del horno que aquí hemos descrito más arriba y del otro horno que, según José Martínez nos cuenta, sigue existiendo en el edificio. Estos hornos eran bastante sólidos, pero cada tres o cuatro hornadas de piezas, habían de ser reparados y limpiados.

Tomás Mercedes, hijo de Pedro, nos explicó que el taller y la casa se modificaron en los últimos años de la década de los sesenta y primeros de los setenta, dándosele el aspecto actual al complejo. Este hecho coincide con la reforma del horno: la reducción del mismo para que fuera más controlable. Explicó Tomás Mercedes que su padre, aunque llevaba haciendo alfarería artística desde los años 30 ya (el raspado lo hace en 1939), decidió reorientar la actividad del alfar en los años sesenta-setenta dado que el plástico había desplazado a los cacharros utilitarios de cerámica. De varios alfareros en el taller, se quedaron trabajando Pedro y José allí. El segundo hacía los cuerpos de las piezas sobre todo y Pedro, aunque también modelaba las piezas, centraba sus esfuerzos en la decoración y el estudio de nuevas técnicas.

Llama la atención el tema de los diversos separadores: desde los atifles en aspa de tres apéndices, muy conocidos en la alfarería musulmana, hasta los específicos que se emplearon en el taller por Félix Pérez primero y después y con mayor variedad en el taller de Pedro Mercedes. Téngase en cuenta que la alfarería artística, con diversidad de piezas y soluciones, requería elementos nuevos para evitar fatales roturas en el horno. Por muy bien que resultase el modelado y la decoración, que de forma única e irrepetible inherente definen a la mayoría de las producciones artísticas, sí el proceso del horno fallaba arruinaba el trabajo.

También era crítico el momento de despegar las piezas cocidas de los separadores. Por ello, José Martínez inventó el separador estriado para evitar que se pegasen demasiado las patas de los toros vidriados. Los separadores en campana, lingote y en aspa, por ejemplo, los empleó Félix Pérez. Pero él y José desarrollan los de caja cuadrada, los cilíndricos, las tapas circulares, los de estrías, unas torres de soporte de azulejos, los "pellizcos" para azulejos o las anillas.

Son todos detalles muy elocuentes, no sólo para entender la alfarería tradicional desde tiempos de la Edad Media, sino también para comprender el proceso de fabricación y el porqué de muchos aspectos de la obra de Pedro Mercedes y no sólo las obras en sí. Mencionar, por último, que hemos tenido noticia de los restos arqueológicos de otro horno y otro alfar 
a pocos metros del taller de Pedro Mercedes: es la casa de la familia del informante Gerson Muñoz, en cuya obra de reforma a finales del siglo XX, apareció un horno que los propietarios respetaron cubriéndolo antes de edificar encima.

\section{A modo de epílogo}

A través de estos yacimientos y edificios en restauración, cuyos resultados estaban inéditos hasta ahora, hemos encontrado el rastro de hasta seis ciudades diferentes en Cuenca: musulmana, de repoblación cristiana, del renacimiento, "ciudad convento", ciudad "liberal” del S. XIX y actual. La islámica, sin duda, es la más desconocida, pues aunque su esquema de dos recintos, mezquita y alcazaba estén claros, no lo está ni mucho menos su evolución. Todavía está por definir el papel que juega ese palacio musulmán en la Plaza de Mangana a la espera de definitivas publicaciones. Por otro lado, es la etapa que menos datos arroja, ya que el carácter peculiar de la arquitectura tradicional conquense no solo se ha "colgado" a buena parte de las murallas medievales, sino que ha suprimido la mayor parte de subsuelo que tradicionalmente ha sido excavado para obtener espacio habitable. Esto hace que la metodología de Arqueología de la Arquitectura sea básica para la gestión patrimonial del casco histórico conquense.

La ciudad del la Edad Moderna se deshizo tanto física como simbólicamente de sus murallas y de su castillo. El proceso no fue inmediato sino muy paulatino y prolongado en el tiempo, pues conocemos ocupaciones en los adarves desde los primeros años de la Baja Edad Media. Pero no se trata sólo individuos con poca conciencia de lo público, también fue clave el desafecto a la nobleza levantisca que trataron de apropiarse de parte del poder real. El mejor modo de hacerlo fue apropiarse del edificio que marca su poder. Obviamente, éste no es otro que el propio alcázar real, que fue el escenario de las luchas más traumáticas, hasta el punto que el propio Enrique IV mandó su derribo. Pero el monarca contó con un aliado con el que plantar cara sus rivales: el Obispo Lope de Barrientos. Una de las consecuencias es tras su muerte la construcción de la girola de la Catedral, otro manifiesto arquitectónico del papel que tendría la Iglesia en la gestación de la sociedad moderna.

El clero no sólo fue clave para promover la "limpieza de la fe" que expulsó a infieles e instauró la Inquisición, sino también para desarrollar lo que hemos definido en otro foro como impacto monumental (MUÑOZ, 2009), es decir: la transformación de la imagen de las ciudades de Castilla y Aragón mediante edificios monumentales, la mayoría con bóvedas de crucería y muchos vinculados con la Iglesia de un modo o de otro. El impacto monumental no se acusa tanto en Cuenca, esto no es debido a posteriores transformaciones y episodios traumáticos, que ciertamente influyeron, pero tuvieron un alcance más limitado y circunstancial. En las Vistas de Anton Van Wyngaerde se aprecia cómo la competencia visual de la arquitectura de viviendas tradicionales es brutal: ocultan los edificios emergentes. Pero, por otro lado, muchas de las obras emprendidas en el S. XVI quedaron inacabadas por falta de financiación. Ejemplo de ello es nuestra intervención en la Iglesia de San Andrés.

Aun así, la imagen de un casco histórico constituido por rascacielos y casas colgadas no debe distraernos de la competencia entre el activismo de una Iglesia pedagoga y evangelizadora -que no olvido instituciones educativas como el Colegio de Gramática de Santa Catalina - y el poder del Concejo moderno que también se destacó por obras tales como el Acueducto, el Puente de San Pablo o la Prisión. Otros ejemplos, como el Pósito extramuros, que estaba situado en la calle de las Torres, no han llegado hasta nosotros.

Sin embargo, la bonanza de la corporación local se frustró por las crisis del S. XVII. Las fundaciones religiosas aumentan, en el momento de auge de la Contrarreforma, al mismo tiempo que se reduce paradigmáticamente la población de la urbe y es la Iglesia la que hereda el mecenazgo sociocultural en la Ciudad Alta. 
En el S. XVIII sabemos que siguió siendo Cuenca esa "Ciudad Convento". El Estado borbónico se esforzó también por dotar a la ciudad de los debidos servicios e infraestructuras que faltaban o se habían quedado obsoletas. Recordemos con que versatilidad se solucionaron dos necesidades en el edificio Almudí: la de depósito de grano y la de carnicerías (MUÑOZ, 2010 y MUÑOZ y DOMÍNGUEZSOLERA, 2014). Pero fue mucho menor el montante económico que se pudo hacer llegar a Cuenca desde Madrid, en comparación a los fondos manejados por el Obispado y sus instituciones afines como el tratado Seminario de San Julián. Al final, la ventaja del juego entre estamento clerical y el cuerpo civil, que se da tanto en la ciudad del renacimiento como en la "ciudad convento", fue para el primero. Por tanto, no debe extrañarnos que una de las señas identitarias del futuro estado liberal, sea relegar a la Iglesia de buena parte de sus esferas de poder tradicionales.

La crisis final del S. XVIII durante el reinado de Carlos IV, la Guerra de la Independencia, la pérdida de las colonias americanas, las guerras carlistas, las revoluciones y los pronunciamientos hicieron muy difícil la construcción de un estado-nación burgués en España. No obstante, éste fue una realidad más o menos vertebrada a mediados del S. XIX y, sin embargo, no tendrá amplias capacidades hasta finales de la centuria. Por ello, la huella del Antiguo Régimen materialmente se mantiene y las amplias necesidades del nuevo Estado se tienen que solucionar adaptándose a infraestructuras y construcciones anteriores. Y no habrá excesivas trasformaciones en los mismos hasta las postrimerías del cambio de siglo. La Casa del Corregidor es representativa de esto, pero también el Convento de Carmen, donde se instaló provisionalmente el Gobierno Civil (TROITIÑO, 1995), que tiene que recurrir a la expropiación para procurarse la sede del organismo que debe regir tanto Cuenca como su provincia. En realidad, la falta de infraestructuras solo es algo que comenzaría a solucionarse a principios del S. XX y prácticamente necesitaría de toda la centuria para ir dando satisfacción a las necesidades de una ciudad que llegó a los tiempos contemporáneos sin apenas recursos.

\section{BIBLIOGRAFÍA}

A.A.V.V. (2009): Arquitectura del Renacimiento en España 1488- 1599. Cátedra, Madrid.

ALIOD GASCÓN, J.L. (1997): EI XVIII, un siglo en la Historia de Cuenca. Instituto Juan de Valdés. Cuenca.

ARIZAGA BORUMBURU, A. (1993): El Paisaje Urbano en la Europa Medieval. III Semana de Estudios Medievales, Najera 1992, Logroño, pp. 11-26.

ARIZAGA BORUMBURU, A. (2002): La Imagen de la Ciudad Medieval, la Recuperación del Paisaje Urbano. Universidad de Cantabria, Santander.

AZKÁRATE, A y ESCRIBANO RÚIZ, S. (2014): De la Arqueología Histórica a la Arqueología del Colonialismo. Una reflexión desde la experiencia europea. Vela. Arqueología de los Primeros Asentamientos Urbanos Españoles en la América Central y Meridional, (Vela Cossio, coordinador). Universidad Politécnica de Madrid, Escuela Técnica Superior de Arquitectura de Madrid, pp. 87-109.

BALLESTEROS BERETTA, A. (1949): La Reconquista de Murcia por el infante Don Alfonso de Castilla. Revista Murgetana, No 1, pp. 10-48.

CARO, A. (2002): Ensayo sobre cerámica en Arqueología. Agrija, Sevilla.

CARRERO SANTAMARÍA, E. (2006): El Claustro Funerario en el Medievo o los Requisitos de una Arquitectura de Uso Cementerial. Rev. Liño, Revista Anual de Historia del Arte, 12, pp. 31-43.

CRESSIER, P. (1999), Los capiteles islámicos de Toledo. Entre el Califato y la Taifa: mil años del Cristo de la Luz. Actas del Congreso Internacional (Asociación de Amigos del Toledo Islámico), Toledo, pp. 169-196

CROSSLEY, D. (1990): Post-medieval Archeology in Britain. Continuum International Publishing Group, Leicester \& New York.

CRIADO, F. (1993): Límites y posibilidades de la Arqueología del Paisaje. SPAL, 2, pp. 99-55.

DE CASTRO FERNÁNDEZ, J. Y CUADRADO BASAS, A. (2011): Un Modelo de Fortificación, los Castillos Urbanos de Alfonso VIII de Castilla. Revista Castillos de España, Na 161-162-163, pp. 61-70.

DOMINGUEZ-SOLERA, S. Y MUÑOZ GARCÍA, M. (2012): La Cuenca Subterránea. Ayuntamiento de Cuenca, Cuenca.

DOMÍNGUEZ-SOLERA, S. D. Y MUÑOZ, M. (2014): Arqueología Urbana en Cuenca Capital: últimos descubrimientos. Espacio, Tiempo, Forma, Serie I, 7, pp. 163-210.

DUBY, G. (1980): Los Tres Órdenes o lo Imaginario del Feudalismo. Taurus, Barcelona.

GERBET, M.C. (1997): Las Noblezas Españolas en la Edad Media. Siglos XI - XV. Alianza Universidad, Madrid.

GÓMEZ MARTínEZ, J. (1998): El Gótico Español en la Edad Moderna. Bóvedas de Crucería. Universidad de Valladolid, Valladolid. 
GUTIÉRREZ LLORET, S. (1997): Arqueología, Introducción a la Historia Material de las Sociedades del Pasado. Universidad de Alicante, Valencia.

IBÁÑEZ MARTÍNEZ, P. M. (2006): La Vista de Cuenca desde la Hoz del Huécar (1565) de Van Den Wyngaerde. Diputación de Cuenca, Cuenca.

IZQUIERDO BENITO, R. (2008): La Cultura Material en la Edad Media. Universidad de Granada y Universidad de Castilla la Mancha, Granada,

LATORRE GONZÁLEZ-MORO, P. (1996): La Arqueología de la Arquitectura. Consecuencias Metodológicas de su Aplicación al Proyecto de Restauración. Arqueología de la Arquitectura, Actas, El método Arqueológico Aplicado al Proceso de Estudio en Intervención en Edificios Históricos (Caballero Zoreda y Escrivano Velasco, coordinadores). Junta de Castilla y León, Burgos, pp. 103-122.

LEÓN BATTISTA ALBERTI (2007): De Re Aedificatoria. Edición de Rivera. Akal, Madrid.

LEÓN MELER, F. (2006): Apuntes sobre el gótico de Cuenca en su Catedral. Cuenca.

LÓPEZ VILLAVERDE, A. L. (2006): Inmovilismo Versus Modernización en la Provincia de Cuenca (S. XIX, XX). Ciclo de Conferencias Histocuenca. Caja de Castilla-La Mancha, Cuenca.

MUÑOZ GARCÍA M. (2006): El Edificio Almudí de Cuenca. Tutor E. Gozalbes, UCLM, Campus de Cuenca, trabajo inédito.

MUÑOZ GARCÍA, M. (2008): Los Límites del Espacio, la Catedral Altomedieval y Románica como Fuente Arqueológica, en Rev. Lope de Barrientos, Seminario de Cultura 1, Las Catedrales Españolas. Fuente de Cultura, Historia y Documentación. Cuenca, pp. 189-214.

MUÑOZ GARCÍA, M. A. (2009): Arqueología de la Universidad de Salamanca. en Historia de la Universidad de Salamanca, T.4. Vestigios y Entramados (Rodríguez San Pedro Bezares y Polo Rodríguez, coordinadores). Ediciones de la Universidad de Salamanca, Salamanca, pp. 177-240.

MUÑOZ GARCÍA, M. (2009): Interpretación Arqueológica de una Catedral Gótica, en coor, Builla Gómez, M.A. e Ibáñez Montoya, J. La Catedral de Santa María de Cuenca, Fundación ACS, Madrid, pp. 105-116.

MUÑOZ GARCÍA, M. A. (2010): Diez años de Arqueología de la Arquitectura desde la empresa privada. Reflexiones y un ejemplo práctico. Arqueología Aplicada al Estudio e Interpretación de los Edificios Históricos (De Vega y Martín Morales, coordinadores). Instituto de Patrimonio Cultural del Ministerio de Cultura, Madrid, pp. 237-252.

MUÑOZ GARCÍA, M. Y DÓMINGUEZ-SOLERA, S. D. (2010): Arqueología en el Conjunto Catedralicio de Cuenca y el Palacio Episcopal. Jornadas Nuestro Patrimonio. Delegación de Cuenca de Cultura, Turismo y Artesanía de la Junta de Comunidades de Castilla-La Mancha, pp. 443-492.

MUÑOZ GARCÍA, M.A. Y DOMÍNGUEZ-SOLERA, S. D. (2010): Tras las Murallas de Cuenca. Consorcio de la Ciudad de Cuenca, Cuenca.
MUÑOZ GARCÍA, M. Y DOMÍNGUEZ-SOLERA, S. D. (2011): Arqueología de un Edificio Gótico y su Cimborrio: La Catedral de Cuenca y las Catedrales Plenomedievales de la Corona de Castilla (I), Rev. Lope de Barrientos, 3, Cuenca, pp. 117-202.

MUÑOZ GARCÍA, M. Y DOMÍNGUEZ-SOLERA, S. D. (2013): Arqueología de un Edificio Gótico y su Cimborrio: La Catedral de Cuenca y las Catedrales Plenomedievales de la Corona de Castilla (II), Rev. Lope de Barrientos, 4, Cuenca, pp. 113 - 162.

MUÑOZ GARCÍA, M. Y MILLÁN MARTÍNEZ, J. M. (2007): Arqueología Urbana en el Casco Histórico de Cuenca. En J. M. Millán Nartínez y C. Rodríquez Ruza /Coordinadores), Arqueología de Castilla-La Mancha, Actas de las primeras jornadas, Cuenca del 13 al 17 de diciembre de 2005, Universidad de Castillá-La Mancha, Cuenca. Pp. 483-502.

MUÑOZ SOLIVA, T. (1860): Noticias de todos los Ilustrísimos Señores Obispos que han Regido la Diócesis de Cuenca Aumentadas con los Sucesos Más Notables Acaecidos en sus Pontificados y con muchas Curiosidades Referentes a la Santa Iglesia Catedral y su Cabildo y a Esta Ciudad y Su provincia. Imprenta de Francisco Gómez e Hijo, calle Cordoneros, № 26, Cuenca.

NAVARRO GARCÍA, C. (1998): Educación y Desarrollo en la Provincia de Cuenca; la Enseñanza Primaria del S. XIX. Serie Tesis Doctorales, Ediciones Universidad de Castilla-La Mancha, pp. 333-334.

NOGUERA CAMPILLO, F. (2012): El Brazo Mayor de la Catedral de Cuenca. Configuración Original y Alteraciones Posteriores. Tesis Doctoral Online dirigida por María Josefa Cassinello. Plaza en el Departamento de Construcción y Tecnología Arquitectónicas, Escuela Técnica Superior de Arquitectura de Madrid. http://oa.upm.es/14535/.

PALACIOS GONZALO, J. C. (2003): Trazas y Cortes de Cantería en el Renacimiento Español. Ed. Munilla Lerilla, Madrid.

PALOMO FERNÁNDEZ, G. (2002): La catedral de Cuenca en el contexto de las grandes canterías castellanas en la baja edad media. Diputación de Cuenca, Cuenca.

PEINADO, P; DOMÍNGUEZ-SOLERA, S. D. Y MUÑOZ, M. (2012): Las fortificaciones del a Guerra Civil en el Cerro del Socorro (CUENCA). Actas del IV Congreso de Castellología, Asociación Española de Amigos de los Castillos (Amador Ruibal, coordinador). Asociación Española de Amigos de los Castillos, Madrid, pp. 322 a 326

QUIROS CASTILLO, J. A. Y BENGOETXEA REMENTERÍA, B. (2011): Arqueología (III). Arqueología Medieval y Posmedieval. UNED, Madrid.

RAMOS, I. (2008): Arrestos, cárceles y prisiones en los derechos históricos españoles. Ministerio del Interior, Madrid.

ROKISKI LÁZARO, M. L. (1985): Arquitectura del Renacimiento en Cuenca. Volúmenes I y II. Diputación de Cuenca, Cuenca.

ROKISKI LÁZARO, M. L. (1995): Arquitecturas de Cuenca, el Paisaje Urbano el Casco Antiguo. Volumen I. Junta de Comunidades de Castilla-La Mancha, Toledo. 
TAPETE, D. (2009): Pittura Murale su Supporti non Murali: Embrici, Tegole, terrecotte da Fra'Bartolomeo a Pietro Annigoni, Rev. Progetto Restauro, 52, pp. 10-18.

RODRIGUEZ TEMIÑO, I. (2004): Arqueología Urbana en España. Akal. Barcelona.

SÁNCHEZ BENITO, J. M. (1997): El espacio urbano de Cuenca en el siglo XV. Diputación de Cuenca, Cuenca.

SOLÍAS ARÍS, J. M, HUÉLAMO GABALDÓN, J.M. y COLL CONESA, (1990): El edificio de la Inquisición de Cuenca. Evolución de un programa arquitectónico (1573-1975). Diputación Provincial de Cuenca, Cuenca.

TROITIÑO VINUESA, M. A. (1994): Trabajo de Campo: La Ciudad Alta de Cuenca. Las ciudades españolas a finales del siglo XX: I Coloquio de Geografía Urbana, pp. 207-221.

TROITIÑO VINUESA, M. A. (1995): Arquitecturas de Cuenca. El Paisaje Urbano del Casco Antiguo. Junta de Comunidades de Castilla la Mancha, Toledo.
URENA Y SMENJAUD, R. (1917): Las Ediciones del Fuero de Cuenca. Real Academia de la Historia, Madrid.

VALERA AGUILAR, E. (2002): La Fortaleza Medieval. Junta de Castilla y León, Ávila.

VALERO TEVAR, M.A. (2010): La Plaza Mangana de Cuenca: Avance de las Últimas Investigaciones Arqueológicas. Actas de las Últimas Jornadas de Arqueología de Castilla - La Mancha (Madrigal Belinchón y Perlines Benito, coordinadores), Junta de Comunidades de Castilla la Mancha, Vol. II Toledo, pp. 868 - 919.

WILLIAMSON, P. (1997): Escultura Gótica, 1140-1300. Manuales de Arte Cátedra, Madrid.

YARZA LUACES, J. (1993): Los Reyes Católicos. Paisaje Artístico de una Monarquía. Nerea, Madrid. 